\title{
College Is Not Enough: Higher Education Does Not Eliminate Racial and Ethnic Wealth Gaps
}

\author{
William R. Emmons and Lowell R. Ricketts
}

\begin{abstract}
Differences in college and post-graduate degree attainment alone explain less than half of Black-White and Hispanic-White wealth gaps in a standard wealth regression. Differences in family structure and measures of luck such as income windfalls and inheritances explain even less. Measures of financial decisionmaking, such as the share of housing in total assets and debt ratios, are much more important. Controlling for differences in all of these observable factors simultaneously and adjusting for life-cycle effects, we can explain about 70 percent of the Black-White wealth gap and virtually all of the HispanicWhite and Asian-White wealth gaps, consistent with earlier research. However, this model assumes equal wealth returns to education levels across racial and ethnic groups. Relaxing this assumption, we find significantly different wealth outcomes across racial and ethnic groups within the same education level. This, in turn, weakens the conclusion that racial and ethnic wealth gaps are largely explainable with observable factors. More importantly, the standard approach assumes all families face the same choice and opportunity sets. We investigate an alternative theoretical framework that attributes racial or ethnic group mean differences in education, family structure, financial decisions, and luck not to individual choice or effort in the face of equal opportunities but instead to systemic or structural factors in the past and present. In this model, the share of wealth gaps that can be explained by observables falls below one fifth for Blacks and Hispanics and to about three quarters for Asians. In other words, a structural-determinants framework suggests the vast majority of the Black-White and Hispanic-White wealth gaps may lie beyond the scope of individual actions or marginal policy changes directed at educational attainment, family structure, financial decisionmaking, or even wealth redistribution. Instead, the gaps appear to be deeply rooted in unobservable factors that may include discrimination or other long-lasting disadvantages. (JEL: D31, J15,I24, D63)
\end{abstract}

Federal Reserve Bank of St. Louis Review, First Quarter 2017, 99(1), pp. 7-39.

http://dx.doi.org/10.20955/r.2017.7-39

William R. Emmons is an assistant vice president and Lowell R. Ricketts is a senior analyst at the Center for Household Financial Stability at the Federal Reserve Bank of St. Louis. This article was prepared for presentation at the symposium, "Does College Level the Playing Field? Racial and Ethnic Differences in Family Wealth Among College-Educated Families," sponsored by the Center for Household Financial Stability and the Research Division of the Federal Reserve Bank of St. Louis, May 25-26, 2016.

(c) 2017, Federal Reserve Bank of St. Louis. The views expressed in this article are those of the author(s) and do not necessarily reflect the views of the Federal Reserve System, the Board of Governors, or the regional Federal Reserve Banks. Articles may be reprinted, reproduced, published, distributed, displayed, and transmitted in their entirety if copyright notice, author name(s), and full citation are included. Abstracts, synopses, and other derivative works may be made only with prior written permission of the Federal Reserve Bank of St. Louis. 


\section{Emmons and Ricketts}

Typical Black and Hispanic wealth is about one-tenth of White wealth, while typical Asian wealth is now about two-thirds of White wealth (all measured at the medians of the respective distributions). ${ }^{2}$ Racial and ethnic wealth gaps are much larger than the corresponding income gaps. The conclusions are similar if we adjust for family size or consider means rather than medians or look at various percentiles of the respective wealth distributions.

Proposals aimed at reducing racial and ethnic wealth gaps include better financial training, different behavioral incentives, stronger institutional support, and outright cash transfers. Yet there is little empirical evidence that any of these measures produce meaningful or lasting results for wealth outcomes within a single generation, let alone across generations. The ultimate causes of large and persistent racial and ethnic wealth gaps remain largely unknown.

More ambitious-albeit more daunting - strategies focus on broad-based improvements in academic or job skills and increased higher-education attainment rates. Bridging the "skills gap" or "education gap" presumably would pay off both in the job market, where most income is earned, and in financial decisionmaking, where savings turn into wealth. The hopeful subtext of these strategies is, "If only we could raise the skill levels and educational attainment of Blacks and Hispanics to White or Asian levels, racial and ethnic income and wealth gaps would be greatly reduced if not eliminated." A corollary is, "Nothing else will be as effective." Yet the power of education to address racial and ethnic wealth gaps is unproven. A variety of evidence suggests education-focused strategies have had limited effectiveness in addressing racial and ethnic wealth gaps-at least so far. Several types of evidence point to the limits of education.

First, Asians as a group have significantly higher high school, college, and post-graduate/ professional degree attainment rates than Whites but summary measures of their wealth are lower. ${ }^{3}$ To be sure, younger cohorts of Asians have widened their education advantage vis-à-vis Whites rapidly. The financial payoff may appear in the future-indeed, median family income among Asians already is higher than among Whites, while the wealth gap between the two is declining. Nonetheless, the Asian experience cautions that a direct link between a high level of college and postgraduate degree attainment and high wealth is not automatic.

Second, despite a half century of huge public investments in education-including admittedly uneven progress toward desegregation and parity in primary and secondary educational quality - racial and ethnic high school graduation-rate gaps have declined but remain substantial. Black-White and Hispanic-White college graduation-rate gaps remain large and, unfortunately, appear to be increasing (albeit slowly) among younger cohorts. ${ }^{4}$ Thus, any plan to achieve Black-White and Hispanic-White graduation-rate parity first must overcome the stagnant (high school) or slightly increasing (college) graduation gaps that exist now.

Third, wealth gaps have widened substantially among college graduates of different races and ethnicities during the past two decades. ${ }^{5}$ In particular, the median Black college-graduate family in 2013 had 56 percent less wealth than the median Black college-graduate family in 1992, and the median Hispanic college-graduate family had 27 percent less wealth in 2013 than its 1992 counterpart (both adjusted for inflation). Meanwhile, the median White collegegraduate family in 2013 had 86 percent more wealth than the median White college-graduate family in 1992, while the corresponding increase was 90 percent among Asians. The result is 
that the median White college-graduate family in 2013 had wealth 11 times as large as the median Black college-graduate family and 7 times as large as the median Hispanic collegegraduate family, up from less than 3 times for both groups in 1992. Thus, even reaching college- graduation-rate parity with Whites would not necessarily translate into wealth parity for Blacks and Hispanics.

The fourth body of evidence that higher education does not level the playing field for wealth accumulation is the subject of this paper. We present two sets of regression results that quantify the contributions of many observable factors to family wealth. While educational attainment is strongly statistically related to wealth levels for all racial and ethnic groupsthat is, more education is correlated with higher wealth-its contribution to explaining the overall racial wealth gap is relatively small. That is, race and ethnicity are highly predictive of family wealth even when comparing families with the same education level-for example, postgraduate Whites and postgraduate Hispanics. Therefore, raising Black and Hispanic education levels could reduce but won't necessarily eliminate the overall wealth gaps.

An important contribution of our paper is to explore two distinct theoretical frameworks for understanding racial and ethnic wealth gaps. First, we assume that education, family structure, financial decisions, and various indicators of luck-such as good health or receiving an inheritance-are uncorrelated with race or ethnicity. In other words, every family is free to choose its education level, marital status, financial-support obligations to extended family, the mix of assets and liabilities it holds, and it has equal odds of being healthy or receiving an income windfall or bequest. We call this a "postracial" model of wealth determination; we use $\mathrm{PR}$ as shorthand to refer to models with this framing, which is standard in the literature. ${ }^{6}$ If differences across families in these observable characteristics were to explain completely all differences in wealth, there would be no residual explanatory power attached to a family's race or ethnicity. Conversely, if indicators of race or ethnicity continue to provide predictive power, we would conclude that unobservable factors-such as ongoing discrimination or the legacies of historical or current disadvantages-are at work or that we have not identified all important observable factors.

Our alternative framework explicitly recognizes the possibility that deep-seated or structural factors related to race or ethnicity may systematically matter for wealth outcomes; we refer to models with this framing as SR models (structural racial or ethnic factors). ${ }^{7}$ The key assumption is that families are not all equally free to choose their education, their family structure, or their financial lives or have the same probability of being lucky. Instead, this model assumes there are profound race- or ethnicity-related forces that determine or greatly influence these outcomes. We put this assumption into action by expressing all of the observable variables we study-education, family structure, financial choices, and luck-in deviation form. For example, we define educational attainment as a family head's years of education minus the average years of schooling among all families of the same race or ethnicity and at the same stage of life. ${ }^{8}$ This means that only the idiosyncratic amount of a variable-the "extra" years of schooling compared with one's age- and race-defined peer group-matters in the model for explaining wealth. An important implication is that an SR model attributes more importance to race or ethnicity than a PR model. In effect, the indicator variable for race or 


\section{Emmons and Ricketts}

ethnicity in the SR regression accounts for more of the variation in wealth than in the PR model because group mean differences in observable variables are related to the race or ethnicity indicators by design. While the PR model implies that an entire racial or ethnic group could make "bad choices" about education, family structure, financial decisions, or being lucky, the SR model rules this out by construction. Instead, families in each group make choices around a group mean-some better and some worse for accumulating wealth but all importantly determined by the group mean or norm.

To summarize our key results, observable factors explain about 70 percent of the BlackWhite wealth gap and virtually all of the Hispanic-White and Asian-White wealth gaps when we use a standard PR framework in which families are free to choose everything that affects their wealth. The most important observable factors that explain the gaps are measures of financial decisionmaking, such as the share of durable goods, housing, or financial and business assets in total assets as well as debt ratios. The age of the family head and the year in which we observe the family also are important. Differences in educational attainment are relatively less important, while differences in family structure and luck—such as health status and receipt of an inheritance-contribute even less.

The standard model assumes equal wealth returns to education levels across racial and ethnic groups by assumption. ${ }^{9}$ Relaxing the equal-returns-to-education assumption, we find significantly different wealth returns to education across racial and ethnic groups. This, in turn, partially reverses the previous conclusion that racial and ethnic wealth gaps are largely explainable with observable factors. The unexplained Hispanic-White wealth gap jumps to about 19 percent when we allow wealth returns to education to vary by race or ethnicity; it is only 9 percent when we impose the equal-returns assumption. For Blacks, the unexplainable portion of the wealth gap remains largely unchanged at around 21 percent.

Even more questionable than the assumption of equal wealth returns to education, the standard approach assumes all families face the same opportunity and choice sets. Using the alternative SR framework, in which opportunities and realistic alternatives differ by race or ethnicity, we estimate the share of wealth gaps explainable by observable factors to be less than 5 percent for Blacks and Hispanics and about 60 percent for Asians. ${ }^{10}$ Adjusting for age remains important, while the importance of financial choices-measured as deviations from the peer-group average-is much reduced. The wealth impacts of higher-than-peer-group education, being married, or receiving an inheritance (and many other factors) have virtually no independent explanatory power.

To be sure, the standard approach and our systemic/structural framework may represent lower and upper bounds, respectively, for the role of unobservable factors such as discrimination or other disadvantages in explaining racial and ethnic wealth gaps. Consequently, we suggest that a reasonable range for the potential role of unobservable factors in creating wealth disparities is about 21 to 72 percent for Black families, 19 to 74 percent for Hispanic families, and 10 to 12 percent for Asian families. Said differently, the portion of racial and ethnic wealth gaps we might expect individual initiative or marginal policy changes to permanently affect range between 28 and 79 percent for Blacks, 26 and 81 percent for Hispanics, and 88 and 90 percent for Asians. ${ }^{11}$ The remainder of the gaps await more fundamental change in the nature 


\section{Figure 1}

\section{Median Family Net Worth, by Race/Ethnicity}

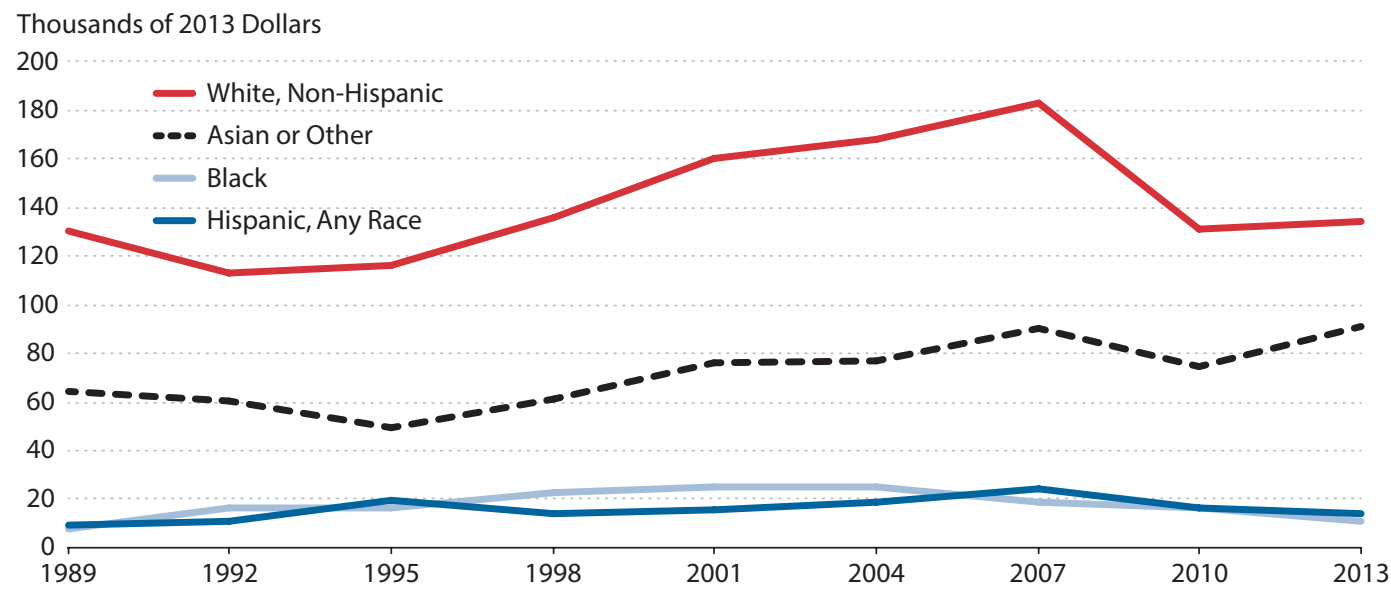

NOTE: All dollar amounts are expressed in 2013 dollars, deflated by the CPI-U (consumer price index for urban consumers) annual series. Due to apparent sampling error, data for Asian or other families in 2004 and 2007 were adjusted by the authors to match the growth rates of median wealth in the overall population. Median family net worth is the value of total assets minus total debts for the family that ranks exactly in the middle of a ranking by net worth.

SOURCE: Federal Reserve Survey of Consumer Finances and authors' calculations.

of our society and the individuals who inhabit it. These large ranges hint at the extent of our ignorance about the ultimate causes of and potential remedies for racial and ethnic wealth gaps.

The paper proceeds as follows. The first section documents large and persistent wealth and income gaps between different racial and ethnic groups. The second section focuses on trends in racial and ethnic wealth gaps among families with four-year college degrees. The third section presents results from what we call a standard PR model of family wealth determination. The fourth section describes an alternative wealth model that assumes choices are not the same for members of every racial or ethnic group due to structural (or other unobservable) factors related to race or ethnicity. The final section concludes.

\section{RACIAL AND ETHNIC WEALTH AND INCOME GAPS 12}

Large persistent differences in wealth and income exist between major racial and ethnic groups in the United States. With few exceptions, the financial patterns evident in 2013 echo those apparent throughout the period since 1989-at least among Whites, Hispanics, and Blacks. Asian families have changed the most during the past 25 years, moving away from Hispanic and Black families' wealth levels toward those of White families.

A simple measure of a household's financial strength is its net worth, or wealth. Figure 1 shows the median inflation-adjusted net worth of each of four racial and ethnic groups at a triennial frequency between 1989 and 2013. The median wealth of White families in 1989 was 


\section{Emmons and Ricketts}

\section{Figure 2}

\section{Median Family Net Worth Relative to Median White Family Net Worth}

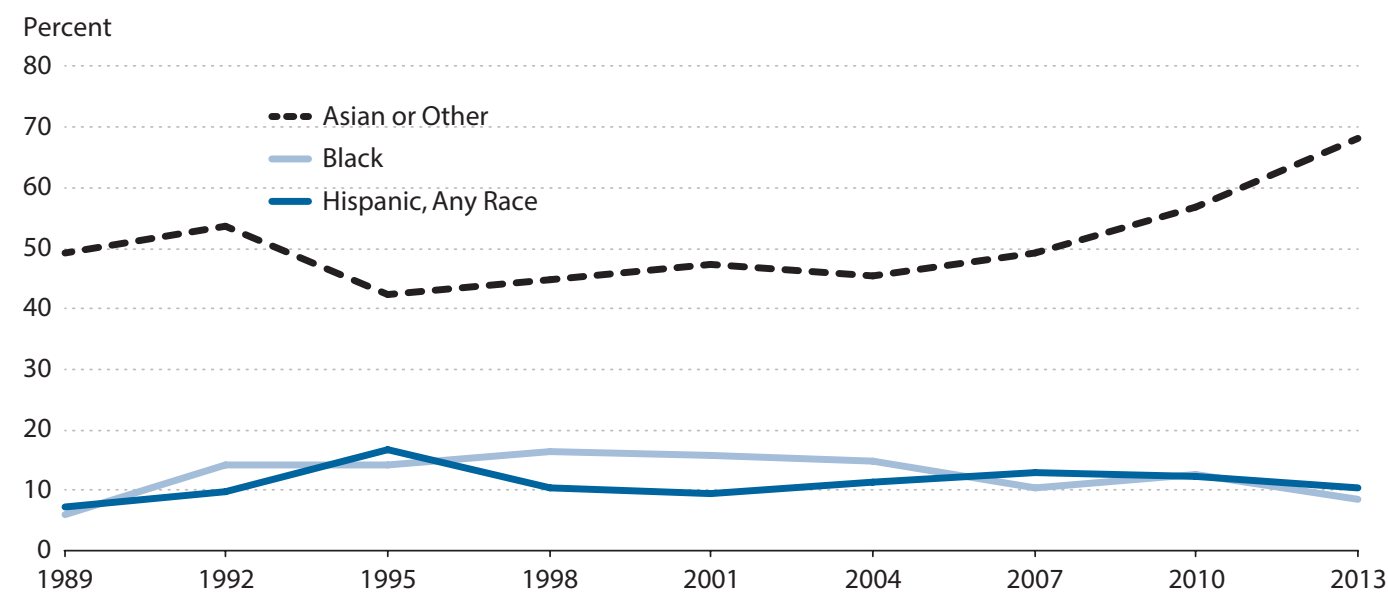

Figure 3

Median Family Income Relative to Median White Family Income

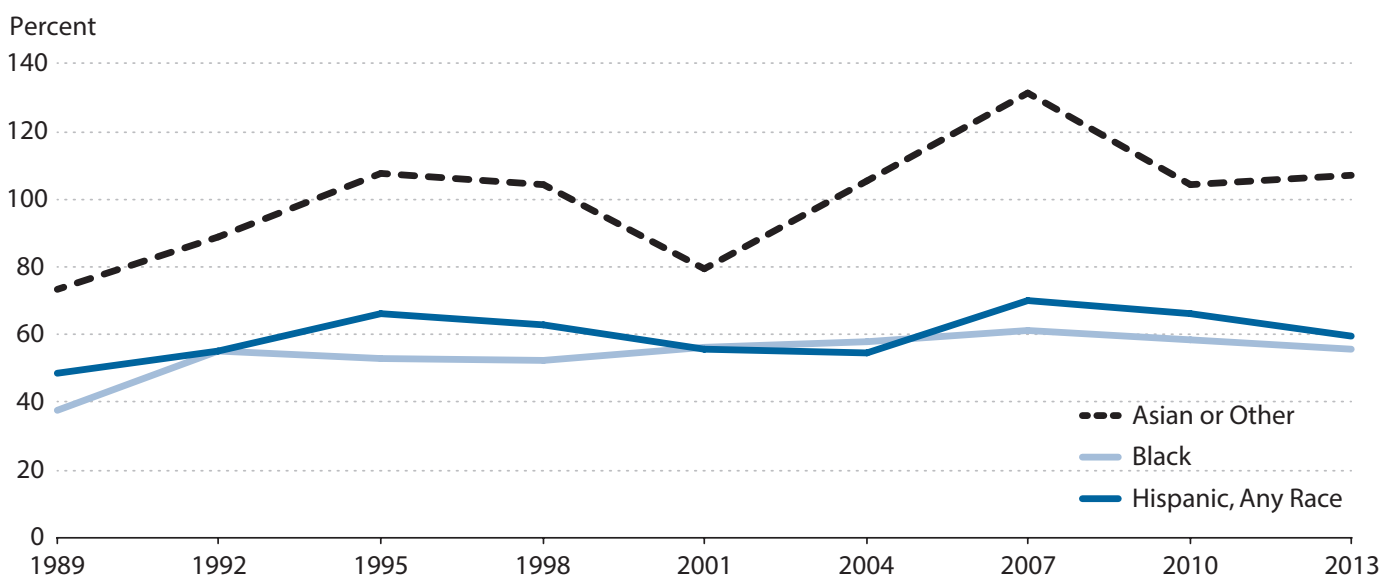

NOTE: Median family income is the value of cash income, before taxes, for the full calendar year preceding the survey for the family that ranks exactly in the middle of a ranking by income.

SOURCE: Federal Reserve Survey of Consumer Finances and authors' calculations. 
just over $\$ 130,000$, while the medians for Asians, Hispanics, and Blacks were about $\$ 64,000$, $\$ 9,000$ and $\$ 8,000$, respectively (all expressed in terms of 2013 purchasing power). The median wealth of each group generally increased until the mid-2000s, after which the medians for all groups declined sharply. In 2013, the median wealth estimates of the four groups were $\$ 134,000$, $\$ 91,000, \$ 14,000$ and $\$ 11,000$, respectively.

Figure 2 shows that the median wealth of Asian families increased more than the median wealth of White families by a significant amount in recent years, rising from 49 percent of the median wealth of White families in 1989 to 68 percent in 2013. Meanwhile, the median wealth of Hispanic and Black families changed little on balance during the quarter-century relative to the median wealth of White families. Median Hispanic wealth increased from 7 to 10 percent of median White wealth between 1989 and 2013, while median Black wealth increased from 6 to 8 percent of median White wealth.

All else equal, higher income may be associated with greater wealth for both direct and indirect reasons. The direct effect is that a higher income may allow a family to save more money because some expenses rise less than proportionately with income, such as food consumed at home, utilities, or commuting costs. Thus, there may be more "slack" in the budget of a family with higher income. The indirect effect is that the same underlying reasons for why someone earns a high income-such as quantitative skills or patience-also may contribute to the quality of financial decisionmaking, affecting financial health and wealth accumulation.

Figure 3 shows that the median family incomes among Hispanic and Black families have remained about 40 percent lower than that for White families since the early 1990s. This fact alone might lead us to expect lower wealth accumulation among Hispanic and Black families. It is possible that White families have a greater ability to save simply because they typically have higher incomes and, therefore, more discretionary income, on average.

The median Asian family income, on the other hand, generally grew faster than that for White families since 1989 and has exceeded the White median income for most of the past two decades. The former will probably continue to grow faster than the latter, given the growing educational achievements of Asians (discussed further in Section 2).

Comparing Figures 2 and 3, two important questions arise-first, why are median Hispanic and Black wealth levels about 90 percent lower than the median White wealth level, while median incomes are only 40 percent lower? Second, why is the median Asian wealth level significantly (30 percent) below that for Whites despite Asians having more education and earning more income for most of the past 20 years?

The answer to the first question may be related to financial behaviors-the indirect links between income and wealth - and/or to factors linked to historical discrimination and disadvantage. We investigate two alternative models of wealth accumulation below. In the first, financial behaviors, such as the share of housing in a family's total assets or the ratio of its debt to its assets, play a large role in explaining differences in wealth across racial and ethnic groups. Results from the second model of wealth accumulation are more consistent with an outsized role for unobservable race- and ethnicity-related factors, which could include a history of discrimination or other disadvantage.

The second question may cease to be an anomaly in the near future. Education, income, and wealth levels are rising rapidly among younger Asian families. If current trends continue, 


\section{Emmons and Ricketts}

\section{Figure 4}

\section{Share of Birth Cohort with At Least a Four-Year College Degree in 2014, Both Sexes}

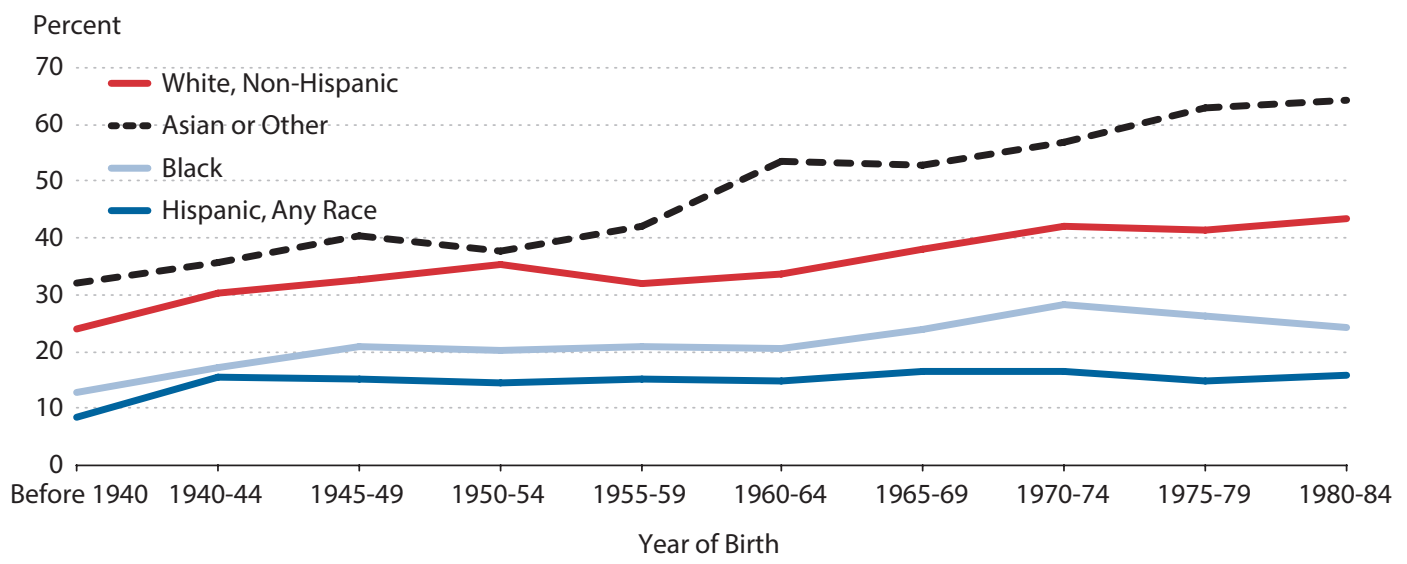

NOTE: The chart shows the share of adults of both sexes with at least a four-year college degree as of 2014. For example, among people born between 1980 and 1984, the share with at least a four-year college degree was 64 percent among Asians, 43 percent among non-Hispanic Whites, 24 percent among Blacks, and 16 percent among Hispanics.

SOURCE: U.S. Census Bureau, Current Population Survey, 2014 Annual Social and Economic Supplement.

the median wealth level among Asian families could surpass that for White families in the near future.

\section{RACIAL AND ETHNIC WEALTH GAPS AMONG COLLEGE-EDUCATED FAMILIES13}

There is a clear rank ordering among races and ethnicities in the U.S. in educationalattainment rates at every level of education. Throughout much of the twentieth and continuing into the twenty-first century, successive birth cohorts have produced a stable ranking of attainment rates; from highest to lowest, they are Asian, White, Black, and Hispanic. For example, Figure 4 shows that, among the young adults who were born in the years 1980-84 (who were between the ages of 30 and 34 in 2014), 64 percent of Asians had obtained at least a four-year college degree by 2014, compared with 43 percent of Whites and only 24 percent of Blacks and 16 percent of Hispanics. Figure 5 shows that 30 percent of Asians born in 198084 had a postgraduate degree, compared with 16 percent of Whites, 8 percent of Blacks, and 5 percent of Hispanics.

The figures also make clear that the Black-White and Hispanic-White college-graduate and postgraduate-degree gaps are generally increasing among successive younger cohorts. Current Population Survey data from the U.S. Census Bureau show that, as of 2014, the fouryear college-graduation gap between Black men and White men had widened to -18.2 percent for the cohort born 1985-89 (ages 25-29 in 2014), versus -14.1 percent for the cohort born 1955-59 (ages 55-59 in 2014); to -20.5 vs. -8.8 percent for Black women; to -25.3 vs. -16.4 


\section{Figure 5}

\section{Share of Birth Cohort with a Graduate or Professional Degree in 2014, Both Sexes}

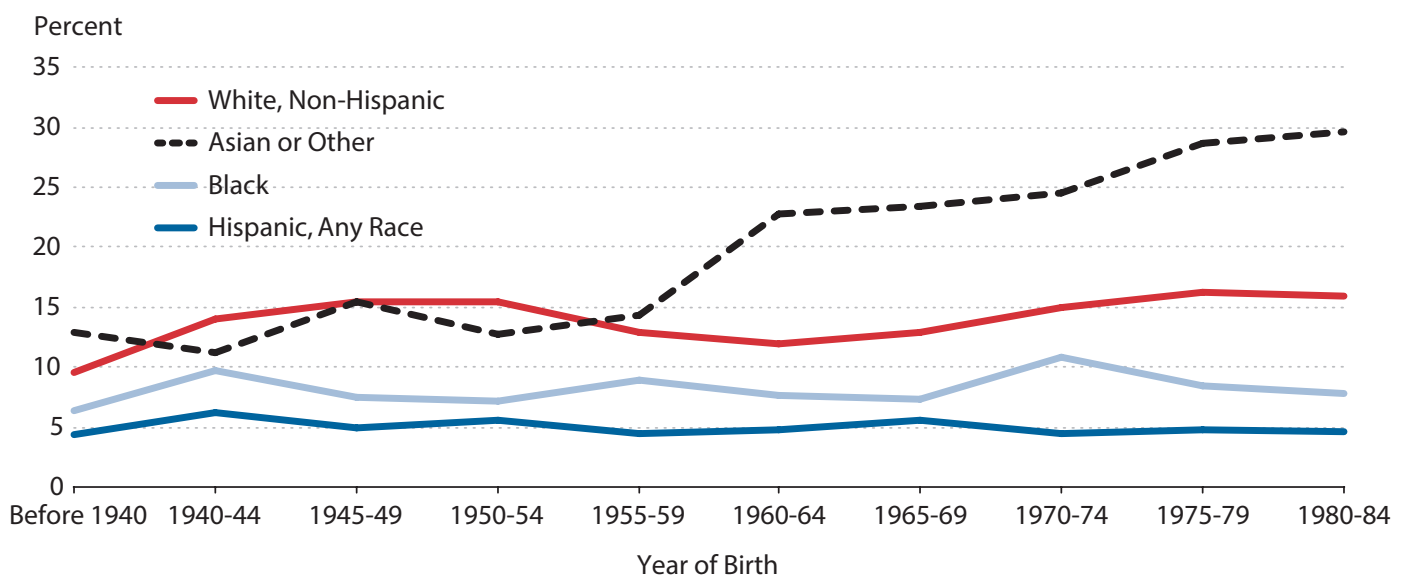

NOTE: The chart shows the share of adults of both sexes with a graduate or professional degree as of 2014 . For example, among people born between 1980 and 1984, the share with a graduate or professional degree was about 30 percent among Asians, 16 percent among non-Hispanic Whites, 8 percent among Blacks, and 5 percent among Hispanics. SOURCE: U.S. Census Bureau, Current Population Survey, 2014 Annual Social and Economic Supplement.

percent for Hispanic men; and to -25.7 vs. -17.0 percent for Hispanic women. In stark contrast, Asian college and postgraduate degree attainment is rising more rapidly than that of Whites, Blacks, or Hispanics. ${ }^{14}$

A particularly disturbing trend is the widening wealth gaps between Black and Hispanic college-educated families on the one hand and White and Asian college-educated families on the other. ${ }^{15}$ Job-market difficulties specific to Hispanic and Black college graduates probably play a role. Financial choices appear even more important in explaining large wealth declines among Hispanic and Black college-educated families during the Great Recession and its aftermath.

\section{Higher Education Typically Boosts Income and Wealth}

The first row of Table 1 shows differences in 2013 median income between families with and without four-year college degrees. The median income among all families headed by someone with a degree was 2.4 times the median income among families headed by someone without such a degree. The ratio was somewhat larger among Whites and Asians than among Blacks and Hispanics, but all were within the range of two to three times larger.

Table 2 shows that higher education is even more strongly associated with wealth accumulation. The typical college-educated family had between 3 and 10 times more wealth than its racial or ethnic counterpart without a degree. The White and Asian wealth ratios shown in the table are noticeably larger than those of Blacks and Hispanics. One reason is that White and Asian college graduates are more likely than Black or Hispanic college graduates to have 


\section{Table 1}

Median Family Income in 2013

\begin{tabular}{lccc} 
& $\begin{array}{c}\text { Four-year } \\
\text { college graduates }\end{array}$ & $\begin{array}{c}\text { Non-college } \\
\text { graduates }\end{array}$ & $\begin{array}{c}\text { Median college income } \\
\text { as a multiple of median } \\
\text { non-college income }\end{array}$ \\
\hline All families & $\$ 87,250$ & $\$ 36,523$ & 2.4 \\
\hline White families & $\$ 94,351$ & $\$ 41,474$ & 2.3 \\
\hline Asian and other families & $\$ 92,931$ & $\$ 32,668$ & 2.8 \\
\hline Hispanic families & $\$ 68,379$ & $\$ 30,436$ & 2.2 \\
\hline Black families & $\$ 52,147$ & $\$ 26,581$ & 2.0 \\
\hline SOURCE: Survey of Consumer Finances and authors' calculations. & & \\
\hline
\end{tabular}

\section{Table 2}

Median Family Net Worth in 2013

\begin{tabular}{lccc} 
& $\begin{array}{c}\text { Four-year } \\
\text { college graduates }\end{array}$ & $\begin{array}{c}\text { Non-college } \\
\text { graduates }\end{array}$ & $\begin{array}{c}\text { Median college net worth } \\
\text { as a multiple of median } \\
\text { non-college net worth }\end{array}$ \\
\hline All families & $\$ 273,586$ & $\$ 43,625$ & 6.3 \\
\hline White families & $\$ 359,928$ & $\$ 80,692$ & 4.5 \\
\hline Asian and other families & $\$ 250,637$ & $\$ 25,632$ & 9.8 \\
\hline Hispanic families & $\$ 49,606$ & $\$ 12,160$ & 4.1 \\
\hline Black families & $\$ 32,780$ & $\$ 9,006$ & 3.6 \\
\hline \multicolumn{2}{l}{ SOURCE: Survey of Consumer Finances and authors' calculations. } & & \\
\hline
\end{tabular}

graduate or professional degrees (recall Figure 5). Advanced degrees typically provide significantly higher earnings and are strongly associated with greater wealth accumulation.

\section{Higher Education Protects Wealth, but Only Among White and Asian Families}

Another financial benefit of having more education may be its "protective" effect on wealth. Better-educated families often withstand major economic and financial shocks better than those with less education. For example, the median wealth (adjusted for inflation) of all families headed by a four-year college graduate declined by 24 percent between 2007 and 2013 and by 48 percent for families with heads without a college degree.

The reasons why having a college degree might appear to protect wealth during turbulent times are complex. They probably include both stronger attachment to and performance in the job market during recessions as well as purely financial factors, including balance-sheet choices and financial behaviors. Education is a strong predictor of the quality of financial decisionmaking.

Figure 6 compares the changes in median wealth between 2007 and 2013 among families headed by four-year college graduates versus those with less education. White and Asian 


\section{Figure 6}

\section{Change in Median Real Net Worth Between 2007 and 2013}

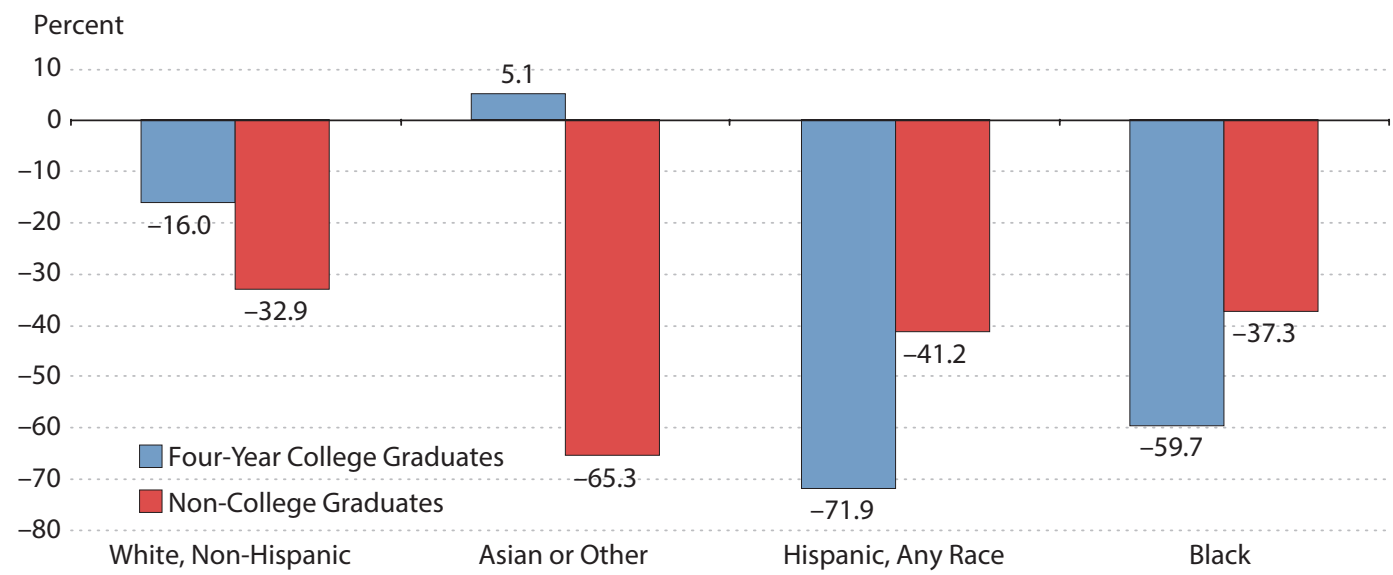

SOURCE: Federal Reserve Survey of Consumer Finances and authors' calculations.

\section{Figure 7}

\section{Change in Median Real Income Between 2007 and 2013}

\section{Percent}

10

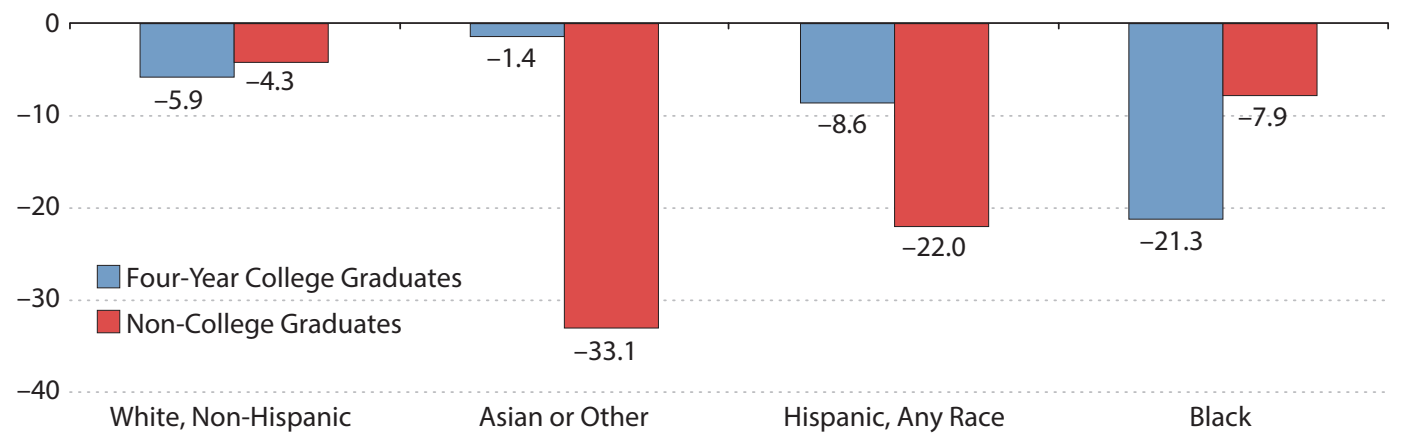

SOURCE: Federal Reserve Survey of Consumer Finances and authors' calculations.

families headed by college graduates generally fared much better than their less-educated counterparts. The typical Hispanic and Black families headed by college graduates, on the other hand, lost much more wealth than their less-educated counterparts. Median wealth of Hispanic families declined by about 72 percent among families headed by a college graduate versus only about 41 percent among families with heads without a college degree. For Blacks, the declines were about 60 percent versus about 37 percent. 


\section{Emmons and Ricketts}

\section{Figure 8}

\section{Median Debt-to-Income Ratios in 2007}

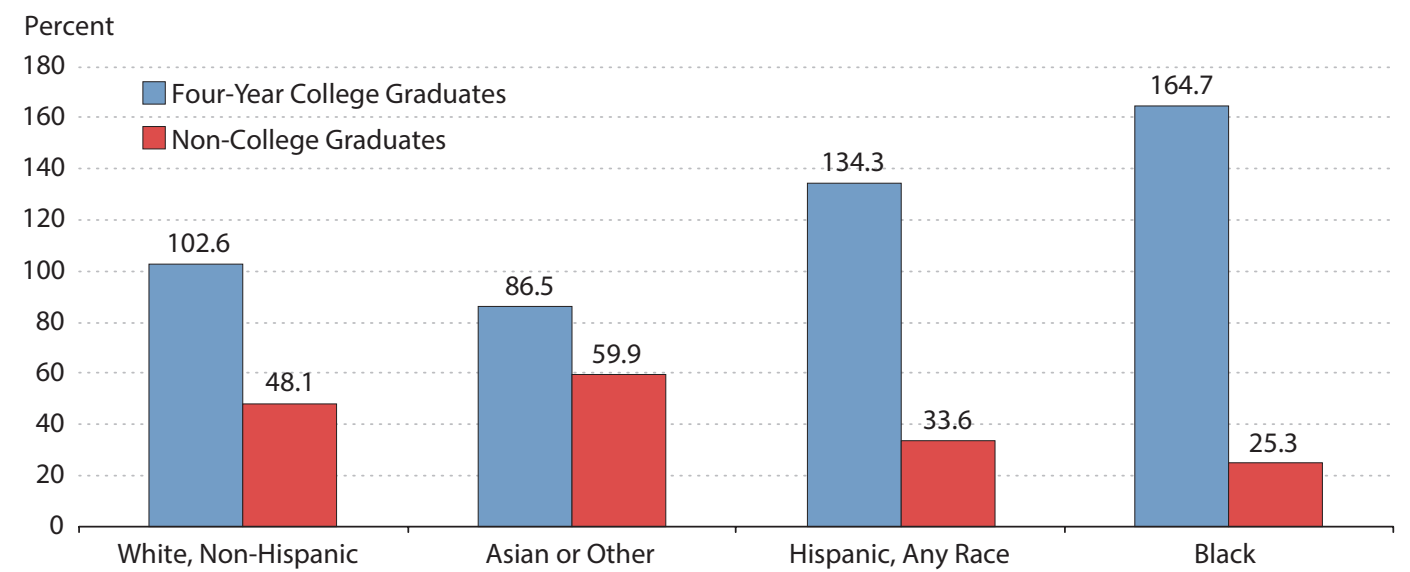

SOURCE: Federal Reserve Survey of Consumer Finances and authors' calculations.

\section{Figure 9}

\section{Change in Median Real Net Worth Between 1992 and 2013}

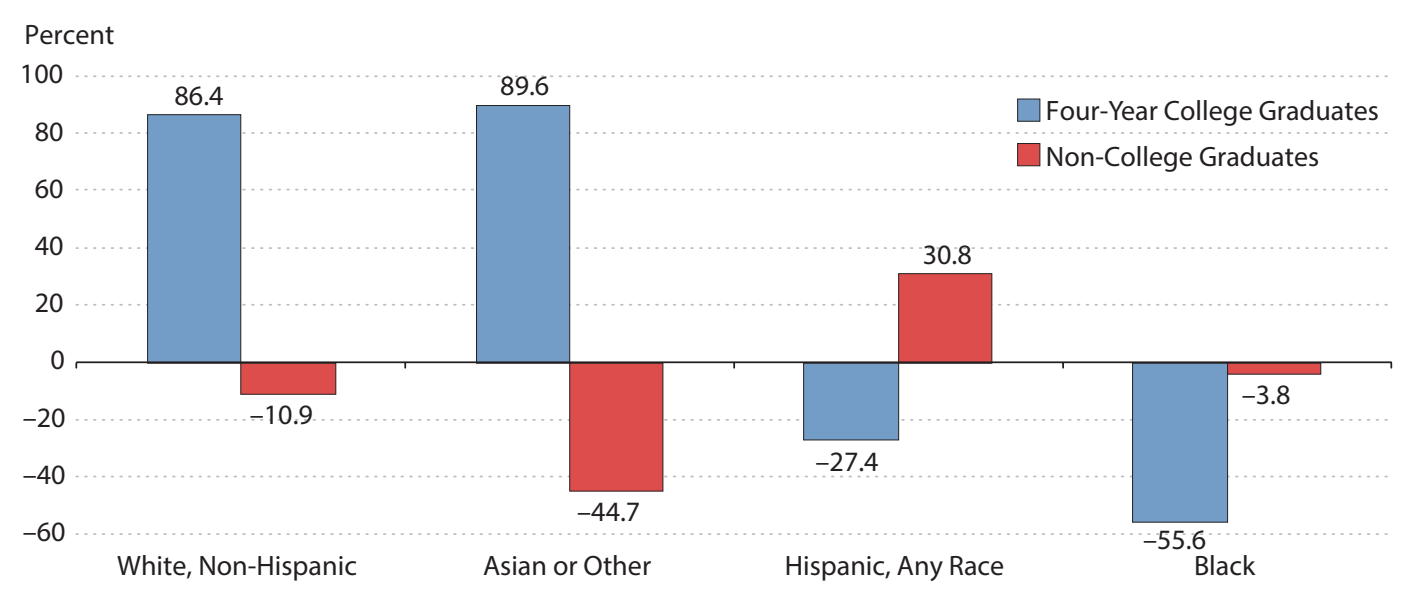

SOURCE: Federal Reserve Survey of Consumer Finances and authors' calculations.

Figure 7 suggests that relative changes in family income may have contributed to more wealth for college-educated Asian families and less wealth for college-educated Black families. However, changes in median incomes among Whites and Hispanics run counter to their respective wealth changes. Therefore, the link between changes in income and changes in wealth is imperfect at best, at least during the most recent economic cycle. 


\section{Figure 10}

\section{Change in Median Real Income Between 1992 and 2013}

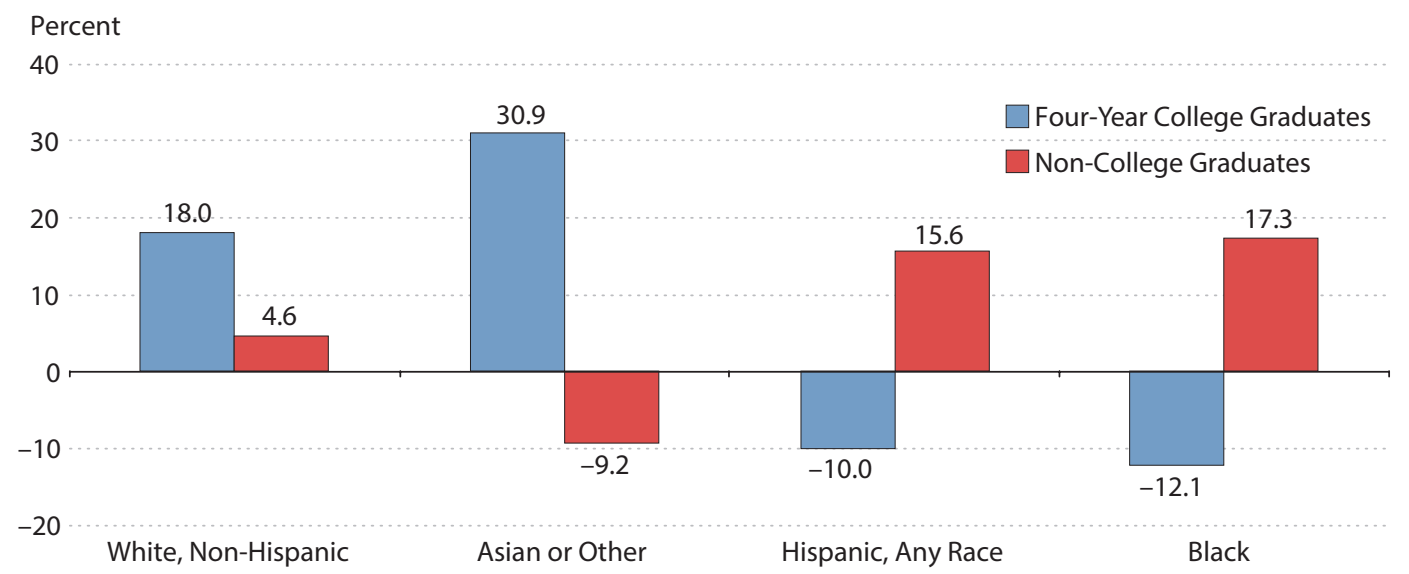

SOURCE: Federal Reserve Survey of Consumer Finances and authors' calculations.

Financial choices probably played a bigger role than income fluctuations in determining wealth outcomes in recent years. Figure 8 shows that the median debt-to-income ratios among college-educated Hispanic and Black families in 2007-on the eve of the Great Recessionwere far higher than those among any other group.

In particular, the typical debt-to-income ratio of a college-educated Hispanic family was four times that of a non-college-educated Hispanic family, while the ratio was close to seven times among Black families. Compounding this potentially severe squeeze on cash flow were balance sheets heavily concentrated in residential real estate, which subsequently plunged in value. Declines in the average value of owner-occupied homes among college-educated Hispanic and Black families between 2007 and 2013 were 45 percent and 51 percent, respectively. The average value of owner-occupied homes declined 25 percent among collegeeducated White families and increased 6 percent among college-educated Asian families.

\section{Income Trends Are Important in the Longer Term}

College graduates typically accumulate much more wealth over long periods than do those without a college degree. The median wealth among all college graduates increased by 52 percent between 1992 and 2013, while the median wealth among all non-college graduates declined by 26 percent. As Figure 9 shows, higher education was strongly associated with greater wealth accumulation among Whites and Asian families, while a college degree was associated with a declining wealth trend for median Hispanic and Black families.

Figure 10 suggests that adverse long-term income trends among Hispanic and Black college graduates may be an important factor in their wealth gaps with White college graduates. The median income of college-educated White families grew by about 13 percentage points more than their less-educated counterparts. The median income of college-educated Asian 


\section{Emmons and Ricketts}

families grew about 31 percent, while the median income of their less-educated counterparts fell about 9 percent over the same period. Conversely, median incomes of college-educated Hispanics and Blacks fell 10 percent and about 12 percent, respectively, while the median incomes of their less-educated counterparts rose about 16 percent and 17 percent, respectively.

In sum, college degrees alone do not provide short-term wealth protection, nor do they guarantee long-term wealth accumulation for all racial and ethnic groups. Given sharply divergent trends in median wealth among college-educated families across racial and ethnic lines, the median college-educated White family in 2013 owned wealth 11 times as large as the median college-educated Black family and 7 times as large as the median college-educated Hispanic family, up from less than 3 times for both groups in 1992.

\section{A PR MODEL OF WEALTH}

The paper closest to the first model in our two-part approach is Thompson and Suarez (2015). This section follows their assumption that the choice set facing every family in the Federal Reserve Board's Survey of Consumer Finances (SCF) is the same regardless of race or ethnicity. That is, observable economic and financial decisions and outcomes are valid independent variables that may explain different wealth outcomes. The key modeling assumption is that, while educational outcomes, family structure, financial decisions, and the outcomes of what we will call luck-including good health, temporary income windfalls and shortfalls, and the receipt of a bequest-may turn out to be correlated with the race or ethnicity of respondent families, this need not have been the case. All families exercise free choice-or in the case of luck, have equal a priori odds of being lucky-and differing wealth outcomes therefore largely reflect different choices, effort levels, or random chance. ${ }^{16}$ As noted, we term this a PR model of wealth.

Our alternative model (see the next section) dispenses with the assumption of identical choice sets and odds of being lucky among all families. As noted, we call this an SR model to denote the relevance of structural racial or ethnic factors. This approach is inspired by Hamilton et al. (2015), who observe that "life outcomes can diverge radically, in particular for those subject to systemic historically rooted discrimination, which is not related to the amount of personal effort exerted" (p. 3).

We suggest the results from the PR and SR models we estimate can be interpreted as lower and upper bounds, respectively, on the role of race or ethnicity per se in determining wealth outcomes. To anticipate our results, in the PR model, race or ethnicity count for almost nothing, while in the SR model they are virtually everything for Black and Hispanic families and a non-trivial factor for Asian families.

\section{Previous Literature}

Both the PR and SR models follow a strategy to identify racial disparities, which was also pursued by Neal and Johnson (1996), Fryer (2011), and Thompson and Suarez (2015), among others. All of these authors considered a sequence of ordinary least-squares regressions in which dummy variables for race or ethnicity are included as explanatory variables along with 
independent variables plausibly linked to the outcome of interest in varying combinations. Neal and Johnson studied wage determination; Fryer updated the Neal and Johnson wage results and extended the model to explore differences in unemployment, incarceration, physical health, and educational outcomes; while Thompson and Suarez adapted the approach to examine family wealth.

Results on the role of racial discrimination or other race or ethnicity-related factors from these studies were mixed. In some cases, controlling for observable factors greatly reduced or eliminated the apparent importance of race or ethnicity in predicting various outcomes; in others, an important role for race or ethnicity remained. Neal and Johnson (1996) used measures of individuals' cognitive skills and levels of education to explain racial or ethnic differences in wages; they concluded that measures of individual skills largely explained racial and ethnic differences in wages received: "While our results do provide some evidence of current labor market discrimination, our primary finding is that large skill gaps between Blacks and Whites are an important determinant of the Black-White wage differences" (p. 892).

Among other outcomes, Fryer (2011) investigated racial and ethnic differences in children's scholastic achievement scores at various ages by supplementing race or ethnicity dummy variables with controls for testing conditions; precise differences in age at the time of testing; gender; region of the country; parents' socioeconomic status; variables to proxy a child's home environment such as family structure, mother's age, and number of siblings; parents' teaching ability; prenatal conditions such as birth weight, premature birth, and multiple births; as well as a host of variables to control for differences in school and teacher quality. ${ }^{17}$ Using several different datasets, Fryer concluded that, from age two onward, observable factors could not explain all of the racial and ethnic test-score gaps.

Thompson and Suarez (2015) employed more than 50 independent variables from the SCF in addition to race and ethnicity dummy variables to model family wealth. They concluded that

$[\mathrm{N}]$ early all of the Hispanic/White wealth gap...can be accounted for by differences in observable traits, with basic demographic characteristics and educational attainment making up most of the gap. Also, most of the White/Black wealth gap can be accounted for by differences in observable characteristics, particularly basic demographic traits and homeownership. Using the full set of observable characteristics discussed in this paper, including home ownership and usual income, we can account for 80 percent of the observed wealth differences between White and Black families (p. 33).

\section{Methodology}

The dependent variable in all of our regressions is the size- and inflation- adjusted net worth of a family after application of the inverse hyperbolic-sine function (IHS). ${ }^{18}$ The IHS transformation is similar to the natural logarithm but has the advantage of preserving observations with nonpositive values of wealth. About 8 percent of SCF families had zero or negative net wealth, so the IHS transformation provides insight into the financial situations of the very poorest families that would be lost using the natural log. To interpret the dummy variables for race or ethnicity that are the primary focus of our study, we apply the Halvorsen-Palmquist 


\section{Emmons and Ricketts}

\section{Table 3}

\section{Wealth Gaps Relative to White Families, PR Model}

\begin{tabular}{|c|c|c|c|c|c|c|c|c|}
\hline Column & (1) & (2) & (3) & (4) & (5) & (6) & (7) & (8) \\
\hline Black families & $\begin{array}{r}-76.3^{* *} \\
(0.00)\end{array}$ & $\begin{array}{r}-71.9^{* *} \\
(0.00)\end{array}$ & $\begin{array}{r}-64.2^{* *} \\
(0.00)\end{array}$ & $\begin{array}{r}-65.0^{* * *} \\
(0.00)\end{array}$ & $\begin{array}{r}-27.0 * * \\
(0.00)\end{array}$ & $\begin{array}{r}-65.5^{* *} \\
(0.00)\end{array}$ & $\begin{array}{r}-22.1^{* *} \\
(0.00)\end{array}$ & $\begin{array}{r}-21.0^{* *} \\
(0.00)\end{array}$ \\
\hline Hispanic families & $\begin{array}{r}-76.0^{* *} \\
(0.00)\end{array}$ & $\begin{array}{r}-64.6^{* *} \\
(0.00)\end{array}$ & $\begin{array}{r}-43.4^{* *} \\
(0.00)\end{array}$ & $\begin{array}{r}-65.3^{* *} \\
(0.00)\end{array}$ & $\begin{array}{r}-17.8^{* *} \\
(0.00)\end{array}$ & $\begin{array}{r}-55.1^{* *} \\
(0.00)\end{array}$ & $\begin{array}{r}-9.2^{* *} \\
(0.00)\end{array}$ & $\begin{array}{r}-18.9^{* *} \\
(0.00)\end{array}$ \\
\hline Asian and other families & $\begin{array}{r}-30.4^{* *} \\
(0.00)\end{array}$ & $\begin{array}{r}-15.8^{* *} \\
(0.00)\end{array}$ & $\begin{array}{r}-27.5^{* *} \\
(0.00)\end{array}$ & $\begin{array}{r}-19.1^{* *} \\
(0.00)\end{array}$ & $\begin{array}{l}15.5^{* *} \\
(0.00)\end{array}$ & $\begin{array}{r}-2.2^{* *} \\
(0.00)\end{array}$ & $\begin{array}{c}5.2^{*} \\
(0.05)\end{array}$ & $\begin{array}{r}10.2^{* * *} \\
(0.02)\end{array}$ \\
\hline Age, birth cohort, year & & $\checkmark$ & $\checkmark$ & $\checkmark$ & $\checkmark$ & $\checkmark$ & $\checkmark$ & $\checkmark$ \\
\hline Educational attainment & & & $\checkmark$ & & & & $\checkmark$ & $\checkmark$ \\
\hline Family structure & & & & $\checkmark$ & & & $\checkmark$ & $\checkmark$ \\
\hline Balance sheet \& financial health & & & & & $\checkmark$ & & $\checkmark$ & $\checkmark$ \\
\hline Luck & & & & & & $\checkmark$ & $\checkmark$ & $\checkmark$ \\
\hline Race $\mathrm{x}$ education interaction & & & & & & & & $\checkmark$ \\
\hline$R^{2}$ & 0.10 & 0.26 & 0.36 & 0.32 & 0.79 & 0.34 & 0.81 & 0.81 \\
\hline
\end{tabular}

NOTE: The dependent variable is the inverse hyperbolic sine of family wealth. Family wealth is divided by the square root of the number of family members. The framework is "postracial," in which the behavioral and environmental variables are entered as observed. The assumption is that these variables are not meaningfully correlated with the race variables. $p$-Value statistics are in parentheses; ${ }^{*}$ and ${ }^{* *}$ denote significance at the 5 percent and 1 percent levels, respectively. A check mark indicates the block of variables was included in the ordinary least squares regression. See Table 1 for variable details. Data are from the Survey of Consumer Finances, comprising seven triennial waves between 1995 and 2013 . Total observations are 34,479, on average, over the five implicates used in each regression. Standard errors are bootstrapped with 999 replications and are adjusted for imputation uncertainty. Sample weights are used in regressions. Coefficients for indicator variables are transformed using the methods of Halvorsen and Palmquist (1980).

(1980) transformation; this renders the co-efficient estimates as percentages. ${ }^{19}$ To adjust for family size, we divide net worth by the square root of the number of immediate-family members; the result is adjusted for inflation using the CPI-U-RS price index. The SCF sample years are $1995,1998,2001,2004,2007,2010$, and $2013 .{ }^{20}$ We use more than 34,400 observations of family units observed in one (and only one) of the seven survey waves. Our definition of educational attainment is partitioned differently from that used in the previous section. "Collegeeducated" families are those where the household head has attained either a 2- or 4-year college degree. Families headed by someone with an advanced degree are included in a "post graduate degree" group. This distinction is important because families headed by someone with a graduate degree typically have much higher net worth than those headed by someone with only an associate or bachelor's degree. ${ }^{21}$

\section{RESULTS FROM A PR MODEL OF WEALTH}

Although our empirical specification differs somewhat from that in Thompson and Suarez (2015), overall results from this section's PR model are similar to those reported in their Table 8 (pp. 48-52). As in Thompson and Suarez, one version of our model explains virtually all (almost 90 percent of) the Hispanic-White wealth gap using observable variables and accounts for about 70 percent of the Black-White wealth gap. Thompson and Suarez do 
not study the Asian-White wealth gap but we do; our model explains that gap completely. Our PR model thus leads to the conclusion reached by Thompson and Suarez-namely, racial and ethnic wealth gaps are due almost entirely to differences in basic demographics (for example, differing age compositions of the groups) and quantifiable differences in behavioral choices including education, family structure, and financial decisions as well as some luck. A feature not explored by Thompson and Suarez is the assumption about the wealth returns to education across racial and ethnic groups. This turns out to be important, as discussed below.

Table 3, Column 1 shows the vast "raw" racial and ethnic wealth gaps evident in the SCF. Compared with White families, Black families are predicted to have 76.3 percent lower wealth, Hispanic families are predicted to have 76.0 percent lower wealth, and Asian families are predicated to have 30.4 percent lower wealth. ${ }^{22}$ All of these estimates are highly statistically significant, with $t$-statistics ranging from 7.7 for Asian families to 62.0 for Black families.

These estimates do not take into account any information about the families except their race or ethnicity (and family size, which is reflected in the transformed dependent variable in all of our regressions). Our empirical strategy is to monitor the race and ethnicity coefficients and the regression's overall R-squared statistic (a measure of variation explained by the regression) as we add blocks of variables (see the appendix for the variables used in our study). The simple model in Column 1 explains about 10 percent of the observed variation in wealth, as indicated by the R-squared statistic.

\section{Basic Controls}

Column 2 adds three potentially important pieces of information to account for variation beyond the control of individual families - a cubic function of age of the family head to capture wealth-relevant life-cycle effects; year dummies reflecting SCF survey dates and therefore the ups and downs of average wealth over time; and a set of dummy variables to allow for birth-year cohort effects. ${ }^{23}$ Controlling for age, survey year, and birth year, the remaining wealth gaps associated with race or ethnicity decline to -71.9 percent, -64.6 percent, and -15.8 percent for Black, Hispanic, and Asian families, respectively. The amount of wealth variation explained increases to 26 percent. If age, survey year, and birth year explained the raw racial and ethnic wealth gaps entirely, coefficient estimates on the race and ethnicity dummy variables would be close to zero and the R-squared statistic might be much larger. Because this is not the case, we proceed with additional factors that may help explain the wealth gaps.

\section{Education}

Columns 3 through 6 add four blocks of variables in turn, which include variables we associate with educational attainment, family structure, financial behavior, and luck, respectively. Adding the highest level of education of the family head to the specification in column 3 shows that the remaining unexplained wealth gaps decline to -64.2 percent and -43.4 percent for Black and Hispanic families, respectively, while the gap increases to -27.5 percent for Asian families. The relatively large reduction in the Hispanic coefficient (from -64.6 percent to -43.4 percent) suggests that the lower average level of education among Hispanics is an important factor explaining their typically lower wealth; among Black families, the reduction 


\section{Emmons and Ricketts}

is much smaller (from -71.9 percent to -64.2 percent), reflecting the somewhat smaller education gap between Blacks and Whites than between Hispanics and Whites.

For Asians, the education effect works in reverse. Asians typically are better educated than Whites, so to hold education levels constant in a comparison with Whites, the regression effectively penalizes Asians. In other words, if Asians had the same (lower) level of education as Whites, the unexplained wealth gap would be 27.5 percent, not 15.8 percent.

Not surprisingly, the model estimates very strong positive connections between each successive level of educational attainment and wealth. Overall, the model explains 36 percent of the wealth variation we observe. Note, however, that the inclusion of education of the family head reduces the unexplained racial and ethnic wealth gaps shown in column 2 by only 11 percent and 33 percent for Black and Hispanic families, respectively, after controlling for age, survey year, and birth year. Among Asians, the inclusion of education actually increases the unexplained wealth gap by 74 percent. In each case, the amount of the racial wealth gap explained by differing levels of education is far less than half and even goes in the opposite direction for Asians.

\section{Family Structure}

Column 4 adds four variables to the model described in column 2 that we interpret as elements of family structure-whether the family head is married or living together with another adult; how many children are in the household; whether the family provides financial support to extended family; and, if so, what fraction of the giving family's income that support represents.

As expected, the model predicts wealth to be much higher for married (or cohabiting) couples than for single adults (even after adjusting for family size). Families that provide assistance to extended-family members also are wealthier, suggesting that this variable helps identify financially stronger families whose gifts do not materially reduce their wealth. Although some families may provide so much support to extended family that it compromises their own financial situation, this effect is not evident in the overall sample. Perhaps surprisingly, neither the number of children in the household nor the amount of financial support provided as a share of family income is a significant predictor of wealth.

The contribution of family-structure variables to explaining racial and ethnic wealth gaps is very small. Estimates of the unexplained gaps fall by only 7 percentage points for Black families (from -71.9 percent to -65 percent) compared to the model in column 2; for Hispanics and Asians, the unexplained gaps rise by 1 and 3 percentage points, respectively, (from -64.6 percent to -65.3 percent and from -15.8 percent to -19.1 percent, respectively.) Just as Asians had more education than Whites, Asians and Hispanics have "stronger" family structures than Whites, as estimated by the model.

\section{Financial Behaviors}

Column 5 examines the wealth effects of financial choices as measured by assets and liabilities on families' balance sheets and an index of their "financial health." 24 In sharp contrast to the relatively small influence of educational attainment, family structure and luck (described below) on racial wealth gaps, differences in financial behaviors are very important. Including an extensive set of variables characterizing family assets and liabilities as well as a summary 


\section{Table 4}

\section{Details on Financial Variables in the Regression Reported in Table 3, Column 5}

\begin{tabular}{lccc} 
Variable name & Type of variable & \multicolumn{1}{c}{$\begin{array}{c}\text { Sign of estimated coefficient: } \\
\text { Relationship with family net worth }\end{array}$} & t-statistic \\
\hline Own durable goods (DG) & Dummy in set $\{0,1\}$ & Positive & Negative \\
\hline Share of DG in total assets & Continuous on $[0,100]$ & Positive & -60.7 \\
\hline $\begin{array}{l}\text { Own residential real estate } \\
\text { (RRE; used as primary residence) }\end{array}$ & Dummy in set $\{0,1\}$ & Negative & 55.9 \\
\hline Share of RRE in total assets & Continuous on $[0,100]$ & Positive & -47.7 \\
\hline Own safe and liquid assets (SLA) & Dummy in set $\{0,1\}$ & Negative & 54.0 \\
\hline Share of SLA in total assets & Continuous on $[0,100]$ & Positive & -45.8 \\
\hline Own financial or business assets (FBA) & Dummy in set $\{0,1\}$ & Positive & 20.6 \\
\hline Share of FBA in total assets & Continuous on $[0,100]$ & Positive & 8.9 \\
\hline Owe non-mortgage debt (NMD) & Dummy in set $\{0,1\}$ & Negative & 2.7 \\
\hline Ratio of NMD to total assets & Continuous on $[0, \infty]$ & Positive & -61.9 \\
\hline Owe mortgage (home-secured) debt (MD) & Dummy in set $\{0,1\}$ & Negative & 27.9 \\
\hline Ratio of MD to total assets & Continuous on $[0, \infty]$ & Positive & -75.1 \\
\hline Financial health score & Integer in set $\{0,1,2,3,4,5\}$ & & 15.9 \\
\hline
\end{tabular}

measure of day-to-day family financial management (Table 4) drops the unexplained portion of racial and ethnic gaps by 62 percent, 72 percent, and 198 percent for Black, Hispanic, and Asian families, respectively. In other words, a majority of the Black-White and Hispanic-White wealth gaps appear to be driven by differences in balance sheets and the balance sheets of Asian families are even stronger than those of White families. The model's $R$-squared jumps to 0.79 with financial variables included, suggesting that about 80 percent of the wealth variation in the SCF can be explained with this relatively simple model.

Examination of the balance-sheet variables in Table 4 suggests that wealth is strongly predicted by diversified asset holdings and low-but not no-debt. Owning each asset category is a positive predictor for wealth, while "loading up" on any one category generally is a negative predictor. Owing any mortgage or non-mortgage debt is a positive predictor, while larger amounts of either kind of debt owed are negative predictors.

The positive coefficient on the concentration of financial and business assets (FBA) dummy variable deserves comment. Only this asset category supports greater wealth when it dominates the asset portfolio; all other asset types (durable goods, safe and liquid assets, and residential real estate) are harmful if they form a concentration. Diversification across the four asset types is desirable. The contribution of our financial health score (FHS) to any of the measures considered here is marginal, but the score itself is highly significant in the regression. As with different asset categories, the FHS is highly correlated with many of the balance-sheet variables.

\section{Luck}

Finally, we examine the effect of luck, which we attempt to capture with three variablestemporary income windfalls or shortfalls; the receipt of a bequest at any time in the past; and 


\section{Emmons and Ricketts}

self-assessed health. Our reasoning is that an unusual surge or decline in a family's income in a given year could be reflected contemporaneously in their wealth but would not necessarily indicate a durable relationship that would continue, so we wish to exclude its effect from our model of wealth determination. Likewise, receiving an inheritance could affect wealth but is not a systematic, on-going contributor to a family's wealth. Finally, we expect poor health to exert a drag on wealth through decreased income from work and increased costs incurred for treatment. Although health certainly is not completely out of our control, we wish to recognize the role of luck in making some people healthier than others.

Column 6 shows that luck as we have measured it makes some difference to racial and ethnic wealth gaps and to the overall explanatory power of our model but is, by no means, the entire story. It turns out that all of the variables included in this category were strongly statistically significant, while having received a gift or inheritance as well as health status were the most meaningful predictors of greater wealth. ${ }^{25}$ Controlling for luck reduces the unexplained wealth gaps by 9 percent for Black families, 15 percent for Hispanic families, and 86 percent for Asian families. The R-squared statistic is 0.34 , comparable with the explanatory power of the model that included education but significantly less than the power of the regression including financial variables.

\section{Full Model Assuming Equal Wealth Returns to Education}

Of the five sets of explanatory variables introduced to explain racial and ethnic wealth gaps, the most important is the financial measures that characterize balance sheets and day-to-day financial management. Just as the variables within each category may be correlated with each other, variables in one category may correlate with those in another-for example, health is correlated with education and homeownership is correlated with marital status. Thus, interpreting individual variables (or groups of variables) in a causal sense is problematic. None of the variables we consider is perfectly correlated with each other, however, so it makes sense to use all of them as we pursue our ultimate objective-an understanding of racial and ethnic wealth gaps.

Column 7 shows the results of the full PR model that includes all of the variables discussed so far; that is, this model assumes that the wealth returns to education are the same across all racial and ethnic groups. First, note that the full model's overall explanatory power is only slightly larger (R-squared of 0.81 ) than the simpler model in column 5 (0.79). In other words, once we include the financial variables, the incremental explanatory power contributed by education, family structure, and luck is very small. Likewise, the amount of racial and ethnic wealth gaps explained by the full model that was not already explained in the model of column 5 is relatively small-the wealth gap to Whites falls from -27 percent to -22.1 percent for Blacks and from -17.8 percent to -9.2 percent for Hispanics. For Asians, the effect is reversed: With only financial variables held constant, Asian family wealth was predicted to be 15.5 percent greater than White family wealth, but with all variables considered, the advantage falls to 5.2 percent. This result corresponds closely to Thompson and Suarez (2015): The Asian-White wealth gap (which they did not consider) is essentially fully explained by observable variables. About 90 percent of the Hispanic-White and 70 percent of the Black-White wealth gaps are explained in a model that fits the data quite well. 


\section{Figure 11}

\section{Predicted Wealth by Education Level and Race}

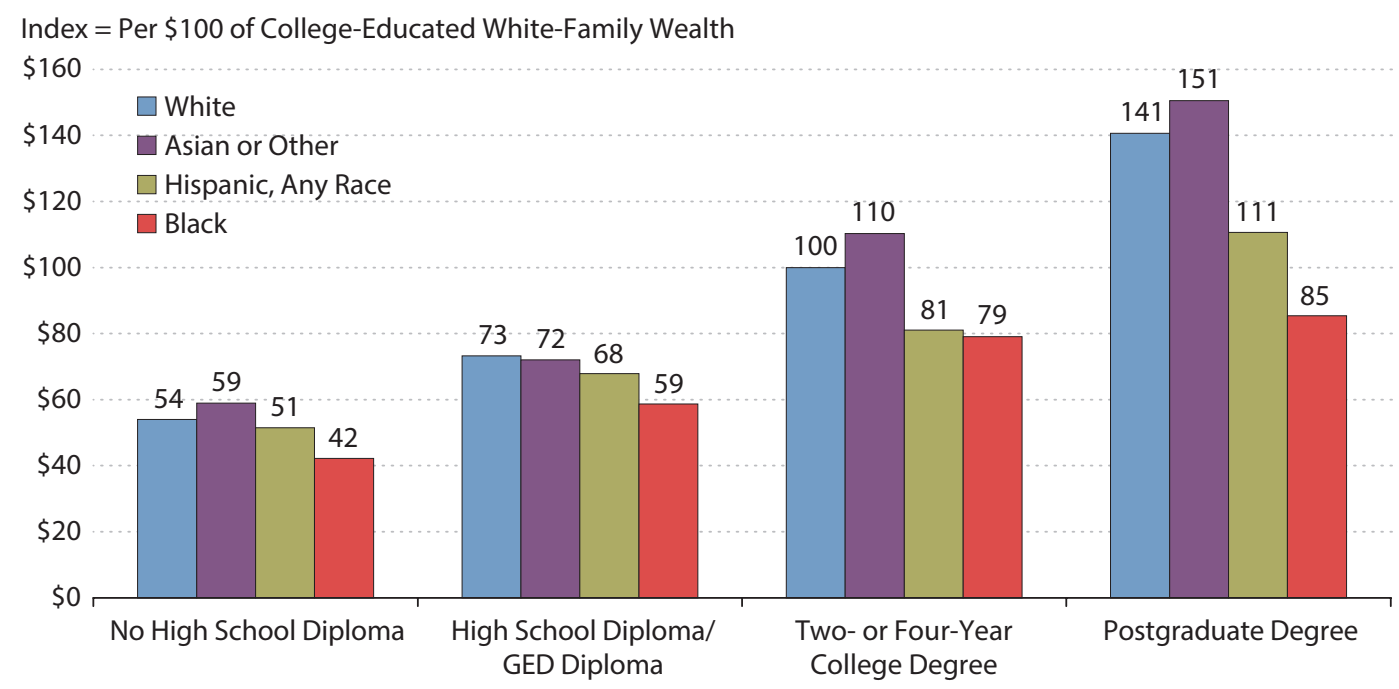

SOURCE: Federal Reserve Survey of Consumer Finances and authors' calculations.

\section{Full Model Allowing Different Wealth Returns to Education by Race or Ethnicity}

An important assumption of the models studied so far is that the link between education and wealth is the same for all families in all racial and ethnic wealth groups. That is, moving from being a high school graduate to a college graduate should result in the same increment to wealth, holding all other factors constant. Is that assumption valid?

Results reported in column 8 suggest the answer is no. Adding a set of interaction dummy variables that allow the wealth returns to different levels of education to differ by race or ethnicity results in the same overall fit of the model. It also reverses some of the apparent explanatory power the earlier models provided for racial and ethnic wealth gaps. In particular, the unexplained portion of the Hispanic-White wealth gap rises from -9.2 to -18.9 percent and the Asian-White advantage rises from 5.2 to 10.2 percent. The interaction variables themselves (not shown) indicate that the equal-wealth-returns-to-education assumption overstates the wealth impacts of successively higher levels of education for Black and Hispanic families by significant amounts. At the same time, forcing the model to equate wealth returns to education across racial and ethnic groups caused the overall estimated returns to education to be smaller than when the assumption is relaxed-that is, the wealth gradient in education is flatter with the equal-returns assumption imposed.

Figure 11 summarizes the relationship between education, race, and wealth estimated by the model in column 8 . For every $\$ 100$ of wealth owned by a college-educated White family (the benchmark family used throughout all of our specifications), the model predicts an Asian college-educated family to have $\$ 110$, a Hispanic college-educated family to have $\$ 81$, and a 


\section{Emmons and Ricketts}

Black college-educated family to have $\$ 79$. These differences cannot be due to differences in educational attainment, because we are comparing families at the same level of education, nor to differences in age, family structure, financial decisionmaking or luck, because the model controls for all of those factors. The ultimate source of the predicted wealth differences must be related to some unobservable aspect of race or ethnicity or to observable factors that we have not included in the model.

Compared with the steep upward progression of expected wealth at successively higher levels of education for White and Asian families, Figure 11 shows wealth trajectories that are much flatter for Hispanic and Black families. Moving from the lowest education level to the highest, the predicted wealth increases from $\$ 54$ to $\$ 141$ for Whites and from $\$ 59$ to $\$ 151$ for Asians but only from $\$ 51$ to $\$ 111$ for Hispanics and from $\$ 42$ to $\$ 85$ for Blacks. Indeed, the predicted gains associated with college and a post-graduate degree are modest for Hispanics and Blacks. These estimates suggest the wealth returns of higher education are substantially higher for Whites and Asians than they are for Hispanics and Blacks.

Another potentially poor assumption in the standard framework is that all individuals and families have equal access to opportunities for education, successful family life, strong balance sheets, and the potential to be lucky. An alternative assumption is that the choice sets of racial and ethnic groups differ. The next section explores a series of wealth models that make this alternative assumption.

\section{A WEALTH MODEL INCORPORATING STRUCTURAL FACTORS RELATED TO RACE OR ETHNICITY}

We recognize potentially important differences in access to opportunity and the range of viable choices facing members of different racial and ethnic groups by transforming most of the independent variables into deviation form. That is, the adjusted value of a variable is its observed value minus the peer-group mean, where the peer group is defined as families of the same race or ethnicity in the same life-cycle stage-young, middle-aged, or old-observed in a range of survey years. See Part B of the appendix for variable definitions and a more detailed description of how we construct the group means.

The result of using variables in deviation form is that only idiosyncratic variation in education, family structure, financial decisions, or luck contribute to the model's explanation of racial and ethnic wealth gaps. Systematic differences across groups therefore are absorbed into the race or ethnicity indicator variables by construction. Because there are, in fact, sizable differences in group means for a number of the independent variables we use, the importance assigned to unexplained forces linked to race and ethnicity in the SR framework necessarily will be greater than in the PR framing. ${ }^{26}$ The question is, how much greater?

\section{Education}

The SR framework begins with the basic model described in Column 2 of Table 4 and proceeds by adding, in turn, each set of explanatory variables expressed in deviation form one at a time. Our approach remains the same-monitor changes in the coefficients on race and ethnicity and compare R-squared statistics as the variable list changes. For ease of reference, the first two columns of Table 3 are repeated in Table 5. 


\section{Table 5}

\section{Wealth Gaps Relative to White Families, SR Model}

\begin{tabular}{|c|c|c|c|c|c|c|c|c|}
\hline Column & (1) & (2) & (3) & (4) & (5) & (6) & (7) & (8) \\
\hline Black families & $\begin{array}{r}-76.3^{* *} \\
(0.00)\end{array}$ & $\begin{array}{r}-71.9^{* *} \\
(0.00)\end{array}$ & $\begin{array}{r}-71.8^{* *} \\
(0.00)\end{array}$ & $\begin{array}{r}-71.9 * * \\
(0.00)\end{array}$ & $\begin{array}{r}-72.3^{* *} \\
(0.00)\end{array}$ & $\begin{array}{r}-71.9^{* *} \\
(0.00)\end{array}$ & $\begin{array}{r}-72.1^{* *} \\
(0.00)\end{array}$ & $\begin{array}{r}-72.0^{* * *} \\
(0.00)\end{array}$ \\
\hline Hispanic families & $\begin{array}{r}-76.0^{* *} \\
(0.00)\end{array}$ & $\begin{array}{r}-64.6^{* *} \\
(0.00)\end{array}$ & $\begin{array}{r}-66.7^{* * *} \\
(0.00)\end{array}$ & $\begin{array}{r}-64.5^{* *} \\
(0.00)\end{array}$ & $\begin{array}{r}-65.6^{* *} \\
(0.00)\end{array}$ & $\begin{array}{r}-64.4^{* *} \\
(0.00)\end{array}$ & $\begin{array}{r}-66.4^{* *} \\
(0.00)\end{array}$ & $\begin{array}{r}-73.6^{* * *} \\
(0.00)\end{array}$ \\
\hline Asian or other families & $\begin{array}{r}-30.4^{* * *} \\
(0.00)\end{array}$ & $\begin{array}{r}-15.8^{* *} \\
(0.00)\end{array}$ & $\begin{array}{r}-16.7^{* *} \\
(0.00)\end{array}$ & $\begin{array}{r}-15.2^{* *} \\
(0.00)\end{array}$ & $\begin{array}{l}15.8^{* *} \\
(0.00)\end{array}$ & $\begin{array}{r}-15.4^{* *} \\
(0.00)\end{array}$ & $\begin{array}{r}-16.2^{*} \\
(0.05)\end{array}$ & $\begin{array}{r}-11.9^{* *} \\
(0.02)\end{array}$ \\
\hline Age, birth cohort, year & & $\checkmark$ & $\checkmark$ & $\checkmark$ & $\checkmark$ & $\checkmark$ & $\checkmark$ & $\checkmark$ \\
\hline Educational attainment & & & $\checkmark$ & & & & $\checkmark$ & $\checkmark$ \\
\hline Family structure & & & & $\checkmark$ & & & $\checkmark$ & $\checkmark$ \\
\hline Balance sheet \& financial health & & & & & $\checkmark$ & & $\checkmark$ & $\checkmark$ \\
\hline Luck & & & & & & $\checkmark$ & $\checkmark$ & $\checkmark$ \\
\hline Race $x$ education interaction & & & & & & & & $\checkmark$ \\
\hline$R^{2}$ & 0.10 & 0.26 & 0.35 & 0.32 & 0.77 & 0.34 & 0.79 & 0.79 \\
\hline
\end{tabular}

NOTE: The dependent variable is the inverse hyperbolic sine of family wealth. Family wealth is divided by the square root of the number of family members. The SR framework reflects structural factors related to race or ethnicity. In particular, independent variables representing education, family structure, financial decisions, and luck are entered as deviations from group means. The group means are calculated for 12 groups-four races or ethnicities times three age groups. The key assumption is that these variables are meaningfully correlated with the race variables. The race dummies absorb the average wealth effects associated with group means. $p$-Value statistics are in parentheses; ${ }^{*}$ and ${ }^{* *}$ denote significance at the 5 percent and 1 percent levels, respectively. A check mark indicates the block of variables was included in the ordinary least squares regression. See Table 1 for variable details. Data are from the Survey of Consumer Finances, comprising seven triennial waves between 1995 and 2013 . Total observations are 34,479, on average, over the five implicates used in each regression. Standard errors are bootstrapped with 999 replications and are adjusted for imputation uncertainty. Sample weights are used in regressions. Coefficients for indicator variables are transformed using the methods of Halvorsen and Palmquist (1980).

Column 3 of Table 5 shows the effect on the unexplained racial and ethnic wealth gaps of adding education in deviation form to the model of column 2. Note first that we define education here as the number of years of completed schooling rather than distinct diploma- or degree-attainment levels. We allow non-linear effects of idiosyncratic educational attainment on wealth by adding squared and cubed terms in education. We chose this approach rather than reducing educational attainment essentially to a four-point scale (as above) so education could enter more flexibly. Otherwise, discrete steps on the scale-such as from no high school diploma to college and from high school to post-graduate degree-would be considered equal (two steps). This seems implausible.

The effect of controlling for deviations in educational attainment from peer-group means on racial and ethnic wealth gaps are very small-essentially zero for Hispanic and Black families. Comparing coefficients from column 3 of Table 5 to those in column 3 of Table 3, it is clear that education's ability to "explain" racial and ethnic wealth gaps in the PR model was based almost entirely on differences in group means. In other words, systematic differences in racial and ethnic educational attainment explained systematic differences in wealth; idiosyncratic differences-what an individual achieves relative to the individual's peer groupare of little consequence. But this seems circular-unexplained racial differences in education are used to explain racial differences in wealth. What explains the racial differences in educa- 


\section{Emmons and Ricketts}

tion? The PR model assigns responsibility for lower educational attainment to individuals; the SR model suggests there are deeper structural or systemic causes.

The R-squared statistic for the model described in column 3 of Table 5 is 0.35 -almost identical to its counterpart in Table 3. This is not surprising because the distribution of educational outcomes is the same in both models (apart from the shift from attainment levels to years of schooling); simply the means of racial and ethnic distributions have been shifted. In effect, the PR model assigns the wealth effects of both the peer-group mean level of education and the idiosyncratic level of education to the education variables, while the SR model assigns the peer-group mean effects to the racial or ethnic indicator variable and attributes only the idiosyncratic level to the education variable.

A direct comparison of the education coefficients themselves in the PR and SR specifications is impossible because we changed the way we measure educational attainment. In both specifications, however, education is strongly related to wealth. All three terms in the cubic function of education we employ in the SR model are highly statistically significant, vindicating our choice of a flexible functional form.

\section{Family Structure}

Column 4 of Table 5 adds four variables in deviation form to the model described in column 2 . These family-structure variables now are the difference between the indicator variable for being married ( 1 if yes, zero otherwise) minus the peer-group mean of this variable; the difference between the number of children in the household minus the peer-group mean number of children; the difference between an indicator variable for providing support to extended family minus the peer-group mean of this variable; and, finally, if so, the difference of the support's share of the family's income from the peer-group mean of this variable.

The two strongly predictive variables from this set in the PR model-marital status and providing support to extended family-remain very strongly related to wealth in the SR model when expressed in deviation form. The number of children in the household in excess of the peer-group mean is a negative predictor in the SR model, similar to the number of children alone in the PR model. The share of income represented by family support remains positive and significant.

The contribution of family-structure variables to explaining racial and ethnic wealth gaps is negligible. Estimates of the unexplained gaps remain largely unchanged for Black and Hispanic families compared with the model in column 2. For Asian families, the unexplained gap falls by less than 4 percent. These effects are much smaller than those found for familystructure variables in the PR model.

\section{Financial Behaviors}

Column 5 of Table 6 examines the wealth effects of financial choices in deviation form. As in the PR model with untransformed financial variables, the fit of the SR model suggests financial variables are the most important in explaining wealth gaps that otherwise would be attributed to the racial and ethnic indicator variables. Nevertheless, removal of peer-group mean differences from the financial variables greatly reduces their effect on the unexplained 
portion of racial and ethnic wealth gaps. In the PR model, inclusion of the financial variables reduced the coefficients by 62, 72, and 198 percent, respectively, for Blacks, Hispanics and Asians. Using de-meaned versions of these variables in the SR model, the gaps actually increase slightly for Black and Hispanic families and are steady for Asian families. As noted above, the R-squared of the models described in column 5 of both Table 3 and Table 5 are close to 0.80 because the total variation explained by the models is essentially the same.

Although the coefficient estimates for the financial variables differ across the two specifications, the overall patterns of signs and statistical significance are very similar. As before, wealth is strongly predicted by diversified asset holdings and low debt.

\section{Luck}

In the final set of potential explanatory variables for racial and ethnic wealth gaps, we consider luck. In deviation form, these variables are the temporary income windfall or shortfall of a family minus the peer-group mean; the difference between an indicator variable for the receipt of a bequest at any time in the past ( 1 if a bequest is received, zero otherwise) and the peer-group mean; and the difference between self-assessed health and the peer-group mean.

Column 6 shows that "idiosyncratic luck" - good or bad fortune relative to the average of the peer group - affects racial and ethnic wealth gaps very little. The reductions in race or ethnicity coefficients is about zero across families. In this specification, all three variables are highly significant in predicting wealth. The R-squared statistic of 0.34 is almost identical to that in the corresponding model in the PR.

\section{Full Model Assuming Equal Wealth Returns to Education}

Surprisingly, race or ethnicity indicator coefficients increase modestly in the full SR model, as compared with reductions for the PR model. Column 7 of Table 5 shows that the indicators increase from -71.9 percent to -72.1 percent for Blacks, from -64.6 percent to -66.4 percent for Hispanics, and from -15.8 percent to -16.2 percent for Asians. In the PR model, the analogous declines were 69 percent, 86 percent, and 135 percent, respectively. The model's measure of overall explanatory power is 0.79 , a slight decline from the PR model's 0.81 . This model imposes equal wealth returns to education by construction. As discussed above, this may overstate the influence of education and understate the unexplained portion of racial and ethnic wealth gaps.

\section{Full Model Allowing Different Wealth Returns to Education by Race or Ethnicity}

Column 8 adds a set of interaction dummy variables that allow the wealth returns to different levels of education to differ by race or ethnicity. These variables are identical in the PR and SR models.

The overall fit of the full SR model is largely unchanged when including the interaction variables. They also reverse some of the apparent explanatory power the earlier models provided for racial and ethnic wealth gaps, as in the PR model. The unexplained portion of the Hispanic-White wealth gap rises from -66.4 percent to -73.6 percent; the Black-White gap is 


\section{Emmons and Ricketts}

largely unchanged at 72 percent; and the Asian-White gap falls slightly from -16.2 percent to -11.9 percent. As before, the interaction variables themselves (not shown) indicate that the equal-wealth-returns-to-education assumption overstates the wealth impacts of successively higher levels of education for Hispanic families by a significant amount. At the same time, forcing the model to equate wealth returns to education across racial and ethnic groups caused the overall estimated returns to education to be smaller than when the assumption is relaxedthat is, the wealth gradient in education is flatter with the equal-returns assumption imposed.

\section{CONCLUSIONS}

Black-White and Hispanic-White wealth gaps are large and persistent. This is due, in part, to large educational-attainment gaps in a world where job-market returns to higher education appear to be increasing. More education is related to better financial decisionmaking, too. This may compound the wealth-accumulation advantages enjoyed by better-educated people who earn higher incomes.

Yet large racial and ethnic wealth gaps exist even among college graduates and among families headed by someone with a graduate or professional degree. In fact, racial and ethnic wealth gaps have become much larger among college graduates of different races and ethnicities in recent decades. Are there other factors that may drive these patterns?

We used comprehensive demographic and financial information from more than 34,400 families surveyed by the Federal Reserve Board during the past quarter century to study the determinants of wealth. A standard model that assumes all families are free to choose their education level, their family structure, their balance sheet, and their odds of being lucky can explain virtually all of the observed wealth gaps between Hispanics and Whites and Asians and Whites. About 70 percent of the Black-White wealth gap is explained by observable factors. In other words, if Hispanics, Asians, and Blacks had the same education, family structure, balance sheets, and odds of being lucky, racial and ethnic wealth gaps would disappear (or diminish greatly in the case of Blacks).

Two alternative assumptions qualify this conclusion, however. First, if we allow racial and ethnic groups to receive different returns to successively higher levels of education, unexplained wealth gaps-that is, the importance of race or ethnicity-rise noticeably. Failing to allow for heterogeneity in wealth returns to education masks relatively higher returns to lesseducated Black and Hispanic families relative to White and Asian families and relatively lower returns to more-educated Black and Hispanic families relative to White and Asian families. The wealth returns to higher education appear to be much higher for White and Asian families than for Hispanic and Black families.

Even more important, the assumption that all families have equal access to opportunity and equal freedom to shape their lives in all important respects (i.e., the standard model) leads to the conclusion that Black and Hispanic families make "bad choices" in large numbers-at least as it relates to wealth accumulation. If, instead, we assume that individual choice is exercised relative to the peer-group means or norms we observe, the conclusions reached in a "postracial" model are dramatically reversed. For Black and Hispanic families, we conclude 
that more than 70 percent of the wealth gaps we observe are related to differences in group means - that is, they may be structural rather than behavioral-with less than 12 percent of wealth variation plausibly determined by individual choices. For Asians, the structural component of the raw wealth gap is about 12 percent.

We conclude that our alternative estimates of the unexplained portions of racial and ethnic wealth gaps represent reasonable lower and upper bounds on the role of unobservable facts such as discrimination or other long-lasting or structural disadvantages. These ranges are large-about 21 to 72 percent for Black families, 19 to 74 percent for Hispanic families, and 10 to 12 percent for Asian families. In other words, the portion of racial and ethnic wealth gaps we might expect individual initiative or marginal policy changes to permanently affect range between 28 and 79 percent for Blacks, 26 and 81 percent for Hispanics, and 88 and 90 percent for Asians. The remainder of the gaps await more fundamental change in the nature of our society and the individuals who inhabit it. These large ranges hint at the extent of our ignorance about the ultimate causes of and potential remedies for racial and ethnic wealth gaps. 


\section{Emmons and Ricketts}

\section{APPENDIX: VARIABLE DEFINITIONS}

\section{A. PR Models}

Categories and variables

Type of variable

Notes

Family wealth

Net worth, calculated as total assets minus total liabilities, divided by the square root of the number

Transformed using the inverse hyperbolic sine function

Scaling parameter, $\theta$, set to 0.0001

\section{Race or ethnicity of the family head}

Non-Hispanic, African-American, or Black

Hispanic/Latino, any race

Non-Hispanic White

Asian and Other

Life cycle

Age of family head at time of survey

Age squared

Age cubed

Survey year

$1998, \ldots, 2013$

1995

Birth cohort

Consecutive five-year cohorts, beginning 1898-1902 (denoted "1900"), ending 1988-92 (denoted "1990")

$1938-42$

Highest level of education of the family head

Less than high school

High school diploma or GED

2- or 4-year college degree

Professional or graduate degree

Family structure

Married

Number of children

Provides support to extended family

Support provided last year to extended family as percent of family income
0 or $1 \quad$ Exactly one race or ethnicity for each family Self-reported in survey

0 or 1

If more than one indicated, use the first one mentioned

0 or 1

Years

Squared years

Cubed years

1 if survey response is in this year, 0 otherwise

Omitted from the regressions

1 if family head was born in one of these cohort years, 0 otherwise Omitted from the regressions

0 or $1 \quad$ Exactly one education level for each family

0 or 1

Omitted from the regressions

0 or 1

0 or 1

1 if married or cohabiting

$0,1,2, \ldots$

0 or 1

Continuous on $[0, \infty)$

Support paid by family $>0$

Cutoff value: $1 / 52$ of "usual" family income or $\$ 1,0002013$ USD 
Emmons and Ricketts

\section{A. PR Models, cont'd}

Categories and variables

Financial behavior

Owner of durable good

0 or 1

Type of variable

Notes

\begin{tabular}{|c|c|c|}
\hline & & income or $\$ 1,0002013$ USD \\
\hline $\begin{array}{l}\text { Share of total assets represented by the value of } \\
\text { durable goods owned }\end{array}$ & Percent, between 0 and 100 & \\
\hline Owner of residential real estate & 0 or 1 & $\begin{array}{l}\text { Cutoff value: 1/52 of "usual" family } \\
\text { income or } \$ 1,0002013 \text { USD }\end{array}$ \\
\hline $\begin{array}{l}\text { Share of total assets represented by the value of } \\
\text { residential real estate owned }\end{array}$ & Percent, between 0 and 100 & \\
\hline Owner of financial and business assets & 0 or 1 & $\begin{array}{l}\text { Cutoff value: 1/52 of "usual" family } \\
\text { income or } \$ 1,0002013 \text { USD }\end{array}$ \\
\hline $\begin{array}{l}\text { Share of total assets represented by the value of } \\
\text { financial and business assets owned }\end{array}$ & Percent, between 0 and 100 & \\
\hline Owes some kind of non-mortgage debt & 0 or 1 & $\begin{array}{l}\text { Cutoff value: 1/52 of "usual" family } \\
\text { income or } \$ 1,0002013 \text { USD }\end{array}$ \\
\hline $\begin{array}{l}\text { Share of total assets represented by the value of } \\
\text { non-mortgage debt owed }\end{array}$ & Percent, 0 or greater & \\
\hline Owes some kind of mortgage (home-secured) debt & 0 or 1 & $\begin{array}{l}\text { Cutoff value: 1/52 of "usual" family } \\
\text { income or } \$ 1,0002013 \text { USD }\end{array}$ \\
\hline $\begin{array}{l}\text { Share of total assets represented by the value of } \\
\text { mortgage debt owed }\end{array}$ & Percent, 0 or greater & \\
\hline Financial health score & $1,2,3,4$, or 5 & $\begin{array}{l}\text { Composite score resulting from five } \\
\text { SCF items; see Emmons and Noeth } \\
\text { (2014) for details. }\end{array}$ \\
\hline \multicolumn{3}{|l|}{ Luck } \\
\hline Income was higher than usual (positive income shock) & 0 or 1 & $\begin{array}{l}\text { Family head responded "Income was } \\
\text { unusually high compared to what they } \\
\text { expect in a 'normal' year." }\end{array}$ \\
\hline Income was lower than usual (negative income shock) & 0 or 1 & $\begin{array}{l}\text { Family head responded "Income was } \\
\text { unusually low compared to what they } \\
\text { expect in a 'normal' year." }\end{array}$ \\
\hline Received a bequest & 0 or 1 & $\begin{array}{l}\text { Cutoff value: 1/52 of "usual" family } \\
\text { income or } \$ 1,0002013 \text { USD }\end{array}$ \\
\hline Health status & 0 or 1 & $\begin{array}{l}\text { Self-reported health of family head, } \\
\text { coded } 0 \text { if poor or satisfactory and } \\
1 \text { if good or excellent }\end{array}$ \\
\hline Race/ethnicity and education interactions & 0 or 1 & $\begin{array}{l}\text { Defined as the intersection of } \\
\text { race/ethnicity and education indicators. } \\
\text { All indicator variables for White families } \\
\text { and 2- to 4-year college-educated } \\
\text { families are omitted. This leaves nine } \\
\text { variables used in the regressions. }\end{array}$ \\
\hline
\end{tabular}




\section{Emmons and Ricketts}

\section{B. SR Models (with Structural Factors Related to Race or Ethnicity)}

Peer Group Definitions: Due to sample-size limitations, we combine survey years into three groups: (i) 1995, 1998, and 2001, (ii) 2004 and 2007, and (iii) 2010 and 2013. Those year groups along with racial/ethnic and age groups create 36 peer groups. We define four racial/ethnic categories as follows: (i) Non-Hispanic White, (ii) Non-Hispanic African-American/Black, (iii) Hispanic, any race, and (iv) other/Asian. We define three age categories: (1) young, headed by someone under 40 years of age; (ii) middle-aged, headed by someone between 40 and 61 years of age; and (iii) old, headed by someone 62 years of age or older.

Categories and variables

Type of variable

Notes

\begin{tabular}{ll}
\hline Family wealth & Defined same as above \\
\hline Race or ethnicity of the family head & Defined same as above \\
\hline Life cycle & Defined same as above \\
\hline Survey year & Defined same as above \\
\hline Birth cohort & Defined same as above \\
\hline
\end{tabular}

Highest level of education of the family head

Adjusted years of education

Continuous on $[-17,17]$.

Actual years minus mean of peer group. NOTE: College education is coded with a maximum of four years of schooling. Graduate school is coded as one year of schooling.

\begin{tabular}{ll}
\hline Adjusted years of education squared & Continuous on $[0,289]$ \\
\hline Adjusted years of education cubed & Continuous on $[-4,913,4,913]$
\end{tabular}

\section{Family structure}

\begin{tabular}{|c|c|c|}
\hline Adjusted marital status & Continuous on $[-1,1]$ & $\begin{array}{l}1 \text { minus mean of peer group if married } \\
\text { or cohabiting, } 0 \text { minus mean of peer } \\
\text { group otherwise }\end{array}$ \\
\hline Adjusted number of children & Continuous on $[-10,10]$ & $\begin{array}{l}\text { Number of children minus mean of } \\
\text { peer group }\end{array}$ \\
\hline $\begin{array}{l}\text { Adjusted indicator for provision of support to } \\
\text { extended family }\end{array}$ & Continuous on $[-1,1]$ & $\begin{array}{l}1 \text { minus mean of peer group if providing } \\
\text { support, } 0 \text { minus mean of peer group } \\
\text { otherwise }\end{array}$ \\
\hline $\begin{array}{l}\text { Adjusted support provided last year to extended } \\
\text { family as percent of family income }\end{array}$ & & Actual share minus mean of peer group \\
\hline \multicolumn{3}{|l|}{ Financial behavior } \\
\hline Adjusted owner of durable goods & Continuous on $[-1,1]$ & $\begin{array}{l}1 \text { minus mean of peer group if owner of } \\
\text { durable goods, } 0 \text { minus mean of peer } \\
\text { group otherwise }\end{array}$ \\
\hline $\begin{array}{l}\text { Adjusted share of total assets represented by the } \\
\text { value of durable goods owned }\end{array}$ & Continuous on $[-100,100]$ & Actual share minus mean of peer group \\
\hline Adjusted owner of residential real estate & Continuous on $[-1,1]$ & $\begin{array}{l}1 \text { minus mean of peer group if owner of } \\
\text { residential real estate, } 0 \text { minus mean of } \\
\text { peer group otherwise }\end{array}$ \\
\hline $\begin{array}{l}\text { Adjusted share of total assets represented by the } \\
\text { value of residential real estate owned }\end{array}$ & Continuous on $[-100,100]$ & Actual share minus mean of peer group \\
\hline Adjusted owner of financial and business assets & Continuous on $[-1,1]$ & $\begin{array}{l}1 \text { minus mean of peer group if owner of } \\
\text { financial and business assets; } 0 \text { minus } \\
\text { mean of peer group otherwise }\end{array}$ \\
\hline
\end{tabular}


Emmons and Ricketts

\section{B. SR Models (with Structural Factors Related to Race or Ethnicity), cont'd}

\begin{tabular}{|c|c|c|}
\hline Categories and variables & Type of variable & Notes \\
\hline $\begin{array}{l}\text { Adjusted share of total assets represented by the } \\
\text { value of financial and business assets owned }\end{array}$ & Continuous on $[-100,100]$ & Actual share minus mean of peer group \\
\hline $\begin{array}{l}\text { Adjusted indicator for owing some kind of } \\
\text { non-mortgage debt }\end{array}$ & Continuous on $[-1,1]$ & $\begin{array}{l}1 \text { minus mean of peer group if owner of } \\
\text { non-mortgage debt, } 0 \text { minus mean of } \\
\text { peer group otherwise }\end{array}$ \\
\hline $\begin{array}{l}\text { Adjusted share of total assets represented by the } \\
\text { value of non-mortgage debt owed }\end{array}$ & Continuous on $[-100,100]$ & Actual share minus mean of peer group \\
\hline $\begin{array}{l}\text { Adjusted indicator for owing some kind of mortgage } \\
\text { (home-secured) debt }\end{array}$ & Continuous on $[-1,1]$ & $\begin{array}{l}1 \text { minus mean of peer group if owner of } \\
\text { mortgage debt; } 0 \text { minus mean of peer } \\
\text { group otherwise }\end{array}$ \\
\hline $\begin{array}{l}\text { Adjusted share of total assets represented by the } \\
\text { value of mortgage debt owed }\end{array}$ & Continuous on $[-100,100]$ & Actual share minus mean of peer group \\
\hline Adjusted financial health score & Continuous on $[-5,5]$. & Actual score minus mean of peer group \\
\hline \multicolumn{3}{|l|}{ Luck } \\
\hline Adjusted negative income shock & Continuous on $[-1,1]$ & $\begin{array}{l}1 \text { minus mean of peer group if } \\
\text { experienced a negative income shock, } \\
0 \text { minus mean of peer group otherwise }\end{array}$ \\
\hline Adjusted positive income shock & Continuous on $[-1,1]$ & $\begin{array}{l}1 \text { minus mean of peer group if } \\
\text { experienced a positive income shock, } \\
0 \text { minus mean of peer group otherwise }\end{array}$ \\
\hline Adjusted receipt of a bequest & Continuous on $[-1,1]$ & $\begin{array}{l}1 \text { minus mean of peer group if received } \\
\text { a gift or bequest, } 0 \text { minus mean of peer } \\
\text { group otherwise. }\end{array}$ \\
\hline Adjusted health status & Continuous on $[-1,1]$ & $\begin{array}{l}1 \text { minus mean of peer group if } \\
\text { self-reported health of family head is } \\
\text { "good" or "excellent," } 0 \text { minus mean of } \\
\text { peer group otherwise }\end{array}$ \\
\hline Race/ethnicity and education interactions & & Same as above \\
\hline
\end{tabular}




\section{Emmons and Ricketts}

\section{NOTES}

1 Emmons and Noeth (2015a).

2 The data we use classify families that are not White, Black, or Hispanic as "other." This group is about 80 percent Asian, so we use the term Asian in what follows even though it also includes Native Americans, Native Hawaiians, Pacific Islanders, and other groups.

3 Emmons and Noeth (2015a).

4 Emmons and Noeth (2015b). Education Department data show that, as of 2014, four-year college-graduation gaps between Black and Hispanic men and women vis-à-vis their White counterparts were larger among people in their early 30 s than among people in their early 60 s.

5 Emmons and Noeth (2015d).

6 See Thompson and Suarez (2015). The term postracial is ours.

7 See Hamilton et al. (2015).

8 The household "head" is a somewhat arbitrary designation in the data used, the Federal Reserve Board's Survey of Consumer Finances: For a mixed-sex couple, the male is considered the head; for a same-sex couple, the older individual is considered the head. For more detailed information regarding the unit of analysis, see the Survey of Consumer Finances codebook at https://www.federalreserve.gov/econresdata/scf/files/codebk2013.txt. For further discussion of the difference between the survey respondent and the designated head, see Lindamood, Hanna, and Bi (2007).

9 The term "wealth return to education" means simply the increment to predicted family wealth associated with the next-higher education level—high school diploma, college, or postgraduate degree or additional year of education in some specifications - holding all other factors constant.

10 These results are from a specification in which wealth returns to education are allowed to differ by race or ethnicity. Imposing equal wealth returns degrades the overall performance of the model slightly, reduces the estimated wealth return to education on average, and decreases the unexplained portion of the racial and ethnic wealth gaps, albeit marginally.

11 The specific policy initiatives covered by our research are those directed at educational attainment, family structure, financial decisionmaking, and wealth redistribution.

12 See Emmons and Noeth (2015a) for an extensive discussion of race, ethnicity, and wealth upon which this section is based.

13 See Emmons and Noeth (2015b) for an extensive discussion of education and wealth.

14 U.S. Census Bureau (n.d.).

15 See Emmons and Noeth (2015d).

16 An inevitable implication of the assumption of free choice is that, if a racial or ethnic group commonly displays a behavior that is negatively associated with wealth, such as a high debt-to-assets ratio, it must be the result of many families making "bad choices."

17 Fryer (2011, p. 868).

18 See Pence (2006).

19 See Halvorsen and Palmquist (1980).

20 We omit observations for the 1989 and 1992 survey years given that questions related to "usual" income and income shocks weren't asked in those years.

21 See Emmons and Noeth (2015b).

22 These figures differ from Figures 1 and 2 because they reflect all families pooled across survey years and considered together. Figures 1 and 2 show medians from each group's distribution in each survey year separately.

23 Emmons and Noeth (2015c) document important wealth effects of birth year. 
24 See Emmons and Noeth (2014) for a description of our financial health score, which was modified slightly for inclusion here.

25 We also investigated the inflation-adjusted size of a bequest received at any time in the past relative to the receiving family's current income. This variable displayed a very large range of values and entered the model with a negative sign, suggesting that the size of an inheritance was negatively related to current wealth. Because we found it implausible that a larger inheritance would make a family poorer and because the range of reported values was so large, we dropped this variable.

26 For example, Pfeffer and Killewald (2015) document sizable differences in the multi-generational transmission of wealth among Black and White families.

\section{REFERENCES}

Emmons, William R. and Noeth, Bryan J. "Economically Vulnerable and Financially Fragile." Federal Reserve Bank of St. Louis Review, September-October 2013, 95(5), pp. 361-88.

Emmons, William R. and Noeth, Bryan J. "Five Simple Questions That Reveal Your Financial Health and Wealth." Federal Reserve Bank of St. Louis In the Balance, 2014, Issue 10.

Emmons, William R. and Noeth, Bryan J. "Race, Ethnicity and Wealth." Demographics of Wealth: How Education and Race Separate Thrivers from Strugglers in Today's Economy, Essay No. 1, Federal Reserve Bank of St. Louis, February 2015a.

Emmons, William R. and Noeth, Bryan J. "Education and Wealth." Demographics of Wealth: How Education and Race Separate Thrivers from Strugglers in Today's Economy, Essay No. 2, Federal Reserve Bank of St. Louis, April 2015b.

Emmons, William R. and Noeth, Bryan J. "Age, Birth Year and Wealth.” Demographics of Wealth: How Education and Race Separate Thrivers from Strugglers in Today's Economy, Essay No. 3, Federal Reserve Bank of St. Louis, July $2015 c$.

Emmons, William R. and Noeth, Bryan J. "Why Didn't Higher Education Protect Hispanic and Black Wealth?" Federal Reserve Bank of St. Louis In the Balance, Issue 12, 2015d.

Fryer, Roland G. Jr. "Racial Inequality in the 21st Century: The Declining Significance of Discrimination," in David Card and Orley Ashenfelter, eds., Handbook of Labor Economics. Volume 4, Part B. Elsevier, 2011, pp. 855-971.

Halvorsen, Robert, and Palmquist, Raymond. "The Interpretation of Dummy Variables in Semilogarithmic Equations." American Economic Review, 1980, 70(3), pp. 474-75.

Hamilton, Darrick; Darity, William Jr.; Price, Anne E.; Sridharan, Vishnu and Tippett, Rebecca. “Umbrellas Don't Make It Rain: Why Studying and Working Hard Isn't Enough for Black Americans." New School, April 2015.

Lindamood, Suzanne; Hanna, Sherman D. and Bi, Lan. "Using the Survey of Consumer Finances: Some Methodological Considerations and Issues." Journal of Consumer Affairs, 2007, 41(2), pp. 195-222; https://doi.org/10.1111/j.1745-6606.2007.00075.x.

Neal, Derek A. Neal and Johnson, William R. "The Role of Premarket Factors in Black-White Wage Differences." Journal of Political Economy, October 1996, 104(5), pp. 869-95; https://doi.org/10.1086/262045.

Pence, Karen M. "The Role of Wealth Transformations: An Application to Estimating the Effect of Tax Incentives on Saving." Contributions to Economic Analysis and Policy, 2006, 5(1); https://doi.org/10.2202/1538-0645.1430.

Pfeffer, Fabian T, and Killewald, Alexandra. "How Rigid Is the Wealth Structure and Why? Inter- and Multigenerational Associations in Family Wealth." Population Studies Center, University of Michigan, 2015.

Thompson, Jeffrey P. and Suarez, Gustavo. "Exploring the Racial Wealth Gap Using the Survey of Consumer Finances." Finance and Economics Discussion Series 2015-076, Board of Governors of the Federal Reserve System, August 2015.

U.S. Census Bureau. "Educational Attainment in the United States: 2015 - Detailed Tables." Accessed December 15, 2016; https://www.census.gov/hhes/socdemo/education/data/cps/2014/tables.html. 
